\title{
America Needs the TREAT Act: Expanding Access to Effective Medication for Treating Addiction
}

Barbara Andraka-Christou

Follow this and additional works at: https://scholarlycommons.law.case.edu/healthmatrix

Part of the Health Law and Policy Commons

\section{Recommended Citation}

Barbara Andraka-Christou, America Needs the TREAT Act: Expanding Access to Effective Medication for Treating Addiction, 26 Health Matrix 309 (2016)

Available at: https://scholarlycommons.law.case.edu/healthmatrix/vol26/iss1/12 


\title{
America NeEDs the TREAT ACT: \\ EXPANDing ACCESS TO EFFECTIVE MEDicAtion FOR TREATING ADDICTION
}

\author{
Barbara Andraka-Christou
}

\section{Contents}

I. The Need for Medication Treatment of Opioid Addiction ..310

II. Overview of Effective Medications .................................... 318

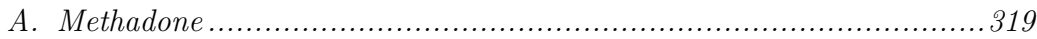

B. Vivitrol...................................................................... 320

C. Buprenorphine .................................................... 321

D. Buprenorphine versus Vivitrol ....................................... 324

E. Buprenorphine versus Methadone...................................... 325

III. Existing Buprenorphine Regulations............................. 327

A. Drug Enforcement Agency Scheduling ................................... 327

B. Drug Addiction and Treatment Act of 2000 ............................. 330

1. Qualified Physicians .............................................................. 332

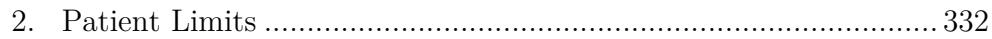

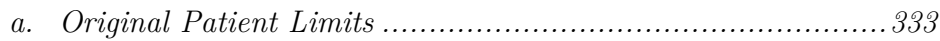

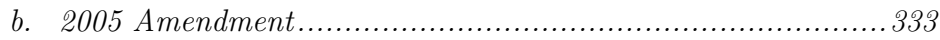

c. 2006 Amendment.............................................. 334

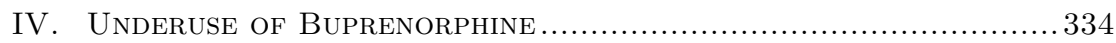

A. Cultural Bias Against MAT ................................................. 335

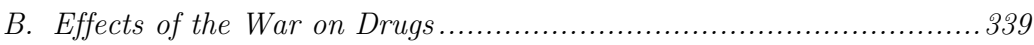

C. Undersupply of Doctors with a DATA Waiver.......................... 342

D. Patient Limits under DATA .......................................... 344

E. Bias from Mental Health Therapists................................. 345

F. Cost and Medicaid Limits .......................................... 346

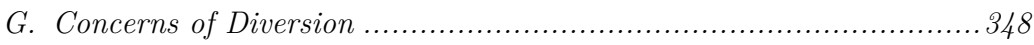

V. The Treat ACT ........................................................ 348

A. Proposed Provisions of the TREAT Act:............................... 349

1. Expansion of the Definition of Practitioner ............................... 349

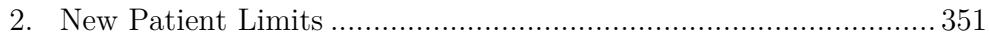

a. Path 1: Practitioners Qualifying via Board Certification ........351

b. Path 2: Practitioners Qualifying via Training Course, Investigating a Clinical Trial, or Other Methods................ 351

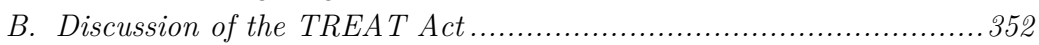

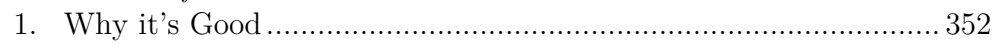

Practicing attorney, member of the Florida Bar Association. Currently pursuing a Ph.D. in Law and Social Science at Indiana University, Bloomington. J.D. Indiana University, Bloomington; B.A. University of Florida. 
Health Matrix · Volume $26 \cdot$ Issue $1 \cdot 2016$

America Needs the TREAT Act:

Expanding Access to Effective Medication for Treating Addiction

2. How to Make the TREAT Act Great......................................... 354

a. Federal Funding for Educational Grants ......................... 355

b. Financial Incentives for Medicaid Coverage of Addiction Medicine

c. Grants for Physician Certification Courses

d. Grants to Study Addiction Medicine Underuse....

VI. Conclusion

\section{The Need for Medication Treatment OF OPIOID ADDICTION}

Opioid overdoses have quadrupled over the last decade in the U.S. ${ }^{1}$ The Drug Enforcement Agency has reported that more people died from drug overdoses in the U.S. in 2013-mostly caused by opioids - than from car accidents. ${ }^{2}$ Some states have been hit especially hard, such as Kentucky, where deaths from heroin overdoses increased by $550 \%$ from 2011 to $2012 .^{3}$ Most individuals who overdose on opioids in the U.S. are addicted to either heroin or prescription painkillers, such as oxycodone. ${ }^{4}$

Approximately 2.1 million individuals in the U.S. are dependent on opioid prescription pain killers, and 467,000 are dependent on heroin. ${ }^{5}$ Opioid dependence has many negative (and often tragic)

1. Li Hui Chen et al., Nat'l Cent. for Health Stat., Drug-Poisoning Deaths Involving Opioid Analgesics: United States 1999-2011 NCHS DATA BRIEF 1 (2014), http://www.cdc.gov/nchs/data/databriefs/db166.pdf.

2. Drug Enforcement Agency, 2015 National Drug Threat ASSESSMENT iii (2015), http://www.dea.gov/docs/2015\%20NDTA \%20Report.pdf. See also Understanding the Epidemic: Overdose deaths in the United States hit record numbers in 2014, CDC.Gov, http://www.cdc.gov/drugoverdose/epidemic/index.html ("The majority of drug overdose deaths (more than six out of ten) involve and opioid... 78 Americans die every day from an opioid overdose").

3. Drug Free Kentucky, Northern Kentucky's Collective Response TO THE HEROIN EPIDEMIC 14 (2013), http://drugfreenky.org/wpcontent/uploads/2013/11/Northern-Kentuckys-Collective-ResponseFinal.pdf.

4. See Chen et al., supra note 1 .

5. America's Addiction to Opioids: Heroin and Prescription Drug Abuse: Hearing on Heroin and Prescription Drug Abuse Before the Senate Caucus on International Narcotics Control (2014) (statement of Nora Volkow, Director, National Institute on Drug Abuse) [hereinafter Hearing on Heroin and Prescription Drug Abuse, http://www.drugabuse.gov/about-nida/legislative-activities/testimonyto-congress/2014/americas-addiction-to-opioids-heroin-prescription-drugabuse. 
consequences for the opioid-dependent individual, his or her family, and society. ${ }^{6}$ Costs to the dependent individual include productivity loss, increased medical costs (especially from emergency room visits and hospitalization), mental distress, and sometimes death. ${ }^{7}$ Costs to society include decreased economic productivity, increased medical costs, and drug-related crimes. ${ }^{8}$ Some cities, like Connersville, Indiana, have been economically devastated by the ripple effects of opioid addiction. ${ }^{9}$

Treatment exists for opioid dependence, but it is underutilized. ${ }^{10}$ In 2013, an estimated 22.7 million Americans were dependent on or abused illicit drugs or alcohol, but only 3 million Americans received treatment for drug dependence. ${ }^{11}$ However, not all treatments for drug dependence are equally effective, and many common misconceptions about effective treatment exist. ${ }^{12}$

6. See, e.g., Substance Abuse and Mental Health Servs. Admin., Substance Abuse Prevention Dollars and Cents: A Cost-Benefits ANALYSIS 6-9 (2008), http://www.samhsa.gov/sites/default/files/costbenefits-prevention.pdf.; $\mathrm{HG}$ Birnbaum et al., Societal Costs of Prescription Opioid Abuse, Dependence, and Misuse in the United States, 12 PAIN MED. 657, 658 (2011).

7. See Birnbaum et al., supra note 6 .

8. See id. at 660-61; Jack Rinehart, Connersville ODs Rise to 36 in Just 2Months, THE INDY CHANnEL (Nov. 6, 2014), http://www.theindychannel.com/news/local-news/connersville-heroinods-rise-to-36-in-two-months. (" 85 percent of the city's crime rate is tied directly to heroin use.")

9. See Network Indiana, Sen. Donnelly Addresses Heroin Overdoses in Connersville, Indiana PuB. MEDIA (Nov. 7, 2014), http://indianapublicmedia.org/news/heroin-problems-continueconnersville-74402/.

10. See Hearing on Heroin and Prescription Drug Abuse, supra note 5.

11. See Behavioral Health Treatments and Services, Substance ABusE AND Mental Health Servs. Admin. (Oct. 16, 2014) http://www.samhsa.gov/treatment.

12. See Maia Szalavitz, After 75 Years of Alcoholics Anonymous, It's Time to Admit We Have a Problem: Challenging the 12-Step Hegemony, PACIFIC STANDARD (Feb. 10, 2014), http://www.psmag.com/books-andculture/75-years-alcoholics-anonymous-time-admit-problem-74268;

Harlan Matusow et al., Medication Assisted Treatment in US Drug Courts: Results from a Nationwide Survey of Availability, Barriers and Attitudes, 44 J. Substance Abuse Treatment 473, 479 (2013) ("Despite evidence of the safety and efficacy of methadone and buprenorphine to improve outcomes for opioid dependence, we found that MAT has limited penetration in drug courts. Lack of adoption of an effective treatment intervention is troubling in light of the increasing problem of opioid abuse in the United States, the large body of growing evidence demonstrating MAT's efficacy in treating it, and the high 
One common misconception is that twelve-step treatment models, such as Narcotics Anonymous (NA) and its identical twin Alcoholics Anonymous (AA), are scientifically proven treatments for opioid dependence. ${ }^{13}$ In fact, many scientists do not consider NA and AA to be evidenced-based treatment for opioid dependence. ${ }^{14}$ The National Institute on Drug Abuse describes twelve-step groups as merely a supplement to effective addiction treatment. ${ }^{15}$ However, twelve-step groups are the primary form of treatment for drug dependence in $90 \%$ of in-patient rehabilitation centers in the U.S. ${ }^{16}$ Very little proof exists that twelve-step groups prevent drug abuse, and many purported studies of effectiveness have failed to distinguish between causation and correlation. ${ }^{17}$ The Journal of Addiction published the results of four rigorous, experimental studies of AA for the treatment of alcoholism; only two studies found a significant positive effect of AA on abstinence, one found a negative effect, and one found no

relapse rates that occur when patients are withdrawn from agonist therapy even when counseling (without MAT) is still available.").

13. See Szalavitz, supra note 12 , at 68 .

14. See Nat'l Inst. on Drug Abuse, U.S. Dep't of Health \& Human Servis., Principles of Drug Addiction Treatment: A ResearchBased Guide, Evidence-Based Approaches to Drug Addiction Treatment 27, 58 (3d ed. 2012) [hereinafter Principles of Drug ADDICTION http://www.drugabuse.gov/publications/principles-drug-addictiontreatment-research-based-guide-third-edition/evidence-based-approachesto-drug-addiction-treatment. ("While the efficacy of 12-step programs (and 12-step facilitation) in treating alcohol dependence has been established, the research on its usefulness for other forms of substance abuse is more preliminary, but the treatment appears promising for helping drug abusers sustain recovery.").

15. See id. at 27 .

16. See Jason Cherkis, Dying to Be Free, Huffington Post (Jan. 28, 2015), https://projects.huffingtopost.com/dying-to-be-free-herointreatment ("Peer-reviewed data and evidence-based practices do not govern how rehabilitation facilities work.").

17. Lee Ann Kaskutas, Alcoholics Anonymous Effectiveness: Faith Meets Science, 28 J. AdDICTION 145, 152 (2008) ("What, then, is the scorecard for AA effectiveness in terms of specificity? Among the rigorous experimental studies, there were two positive findings for AA effectiveness, one null finding, and one negative finding. Among those that statistically addressed selection bias, there were two contradictory findings, and two studies that reported significant effects for AA after adjusting for potential confounders such as motivation to change. Readers must judge for themselves whether their interpretation of these results, on balance, supports a recommendation that there is no experimental evidence of AA effectiveness (as put forward by the Cochrane review)."). 
effect. ${ }^{18}$ The National Institute on Drug Abuse has stated that even fewer studies of NA (the group for drug dependent individuals) exist than of AA (the group for alcohol dependent individuals). ${ }^{19}$

Another common misconception about drug dependence is that detoxification in a controlled setting is sufficient treatment to prevent relapse. ${ }^{20}$ However, detoxification alone is almost never enough to end drug dependence, especially opioid dependence, because the physical changes in the brain persist post-detoxification. ${ }^{21}$ Additionally, the chance of overdose is highest immediately after detoxification, because psychological and physical cravings exist but physical tolerance for opioids is low. ${ }^{22}$

Instead of NA/AA or detoxification alone, the medical standard of care for opioid addiction is medication combined with counseling, frequently referred to as medication assisted treatment (MAT) ${ }^{23}$ This

18. See $i d$.

19. See also Principles of Drug Addiction Treatment, supra note 14 , at 57-58.

20. See Louise Baxter \& Alan Stevens, Am. Soc'y of Addiction Med., The Impact of Managed Care on Addiction Treatment: An ANALYSIS 2 (2012), http://www.asam.org/docs/advocacy/2012-925_nj-opiate-document.pdf?sfvrsn=2; Vt. Agency of Human Services, Integrated Treatment Continuum for Substance Use Dependence "Hub/Spoke" Initiative-Phase 1: Opiate Dependence (Jan. 2012), at 2, http://www.healthvermont.gov/adap/documents/HUBSPOKEBriefingD ocV122112.pdf ("Medication assisted therapy (MAT), such as methadone and buprenorphine in combination with counseling, has long been recognized as the most effective treatment for opiate addiction."); What are the treatments for heroin addiction?, NAT'L INST. ON DRUG ABuse (last updated Nov. 2014), http://www.drugabuse.gov/ publications/research-reports/heroin/what-are-treatments-heroinaddiction.

21. See Dan Lubman et al., Addiction, a condition of compulsive behaviour? Neuroimaging and neuropsychological evidence of inhibitory dysregulation, 99 AdDICTION 1491, 1492 (2004).

22. BAXter \& Stevens, supra note 20, at 2 ("Unfortunately, too many stakeholders in addiction treatment represent that detoxification alone is treatment. "Detoxification alone" only increases the probability of relapse into active use and overdose deaths."); Matusow et al., supra note 12, at 478 ("In light of the ample evidence demonstrating high relapse rates following opioid detoxification, a policy mandating medical withdrawal [from M.A.T.] appears to be contrary to be practices as defined by medical evidence and the consensus of addiction experts and may represent an infringement of rights as set forth in the Americans with Disabilities Act.").

23. See BAXter \& Stevens, supra note 20, at 4; Lisa A. Marsch, The Efficacy of Methadone Maintenance Interventions in Reducing Illicit Opiate Use, HIV Risk Behavior, and Criminality, 93 ADDICTION 515 (1998); Richard P. Mattick et al., Methadone Maintenance Therapy 
standard has been acknowledged by the American Society of Addiction Medicine and the American Medical Association for over a decade but has been largely ignored by most in-patient treatment centers. ${ }^{24}$ In March 2015, the U.S. Department of Health and Human Services affirmed that "MAT is the most effective form of treatment for opioid use disorders." ${ }^{25}$ The most effective medications used as part of MAT for treating opioid addiction are buprenorphine (commonly known by the brand name Suboxone), Vivitrol (extendedrelease naltrexone), and methadone. ${ }^{26}$ Each of these three medicines has been proven significantly more effective at preventing relapse than a placebo in rigorous, double-blind experimental studies. ${ }^{27}$ Medical

versus No Opioid Replacement Therapy for Opioid Dependence, Cochrane Database of Systematic Reviews 1, 5, 10-11 (2009) (noting that medication maintained treatment combined with therapy is more effective than therapy alone); Richard P. Mattick et al., Burprenorphine Maintenance versus Placebo or Methadone Maintenance for Opioid Addiction, Cochrane Database of Systematic Reviews 1, 1, 17, 19 (2009) (noting effectiveness of buprenorphrone vs. placebo); National Consensus Development Panel on Effective Medical Treatment of Opiate Addiction, Effective Medical Treatment for Opiate Addiction, 280 JAMA 1936 (1998); Jeffrey Baxter et al., Factors Associated with Medicaid Patients' Access to Buprenorphine Treatment, 41 J. Substance Abuse Treatment 88 (2011); Heino Stöver, Barriers to Opioid Substitution Treatment Access, Entry and Retention: A Survey of Opioid Users, Patients in Treatment, and Treating and Non-Treating Physicians, 17 Eur. AdDiCTION RES. 44, 44 (2011) ("Opioid substitution treatment (OST) is recognized internationally as the most effective and cost-effective intervention to reduce the social, health and economic burden associated with opioid dependence."); Saxon \& McCarty, supra note 16 , at 122 .

24. See generally BAXTer \& Stevens, supra note 20; What are the treatments for heroin addiction?, supra note 20.

25. U.S. Dep't of Health \& Human Servs., Executive Summary: Opioid Abuse IN THE U.S. AND HHS ACTIONS TO ADDRESS OpIOID-Drug RElAted Overdoses AND DEATHS 3 (2015), http://aspe.hhs.gov/sp/ reports/2015/OpioidInitiative/es_OpioidInitiative.pdf.

26. See What are the treatments for heroin addiction?, supra note 20.

27. See generally Cent. For Substance Abuse Treatment, MedicationAssisted Treatment for Opioid Addiction in Opioid Treatment Programs 32-33 (2012) [hereinafter Medication Assisted Treatment FOR OPIOID ADDICTION], http://www.ncbi.nlm.nih.gov/books/ NBK64164/pdf/TOC.pdf; Angela Stotts et al., Opioid Dependence Treatment: Options in Pharmacotherapy, 10 EXPERT OPINION Pharmacother. 1727 (2009); Kimberly L. Kjome \& F. Gerard Moeller, Long-Acting Injectable Naltrexone for the Management of Patients with Opioid Dependence, 5 Substance Abuse: Res. \& Treatment 1, 4 (2011); Richard Boldt, The "Tomahawk" and the "Healing Balm": Drug Treatment Courts in Theory and Practice, 10 U. MD. L.J. RACE, Religion, Gender \& Class 45, 60 (2010) ("Indeed, methadone 
studies have also found that the combination of medication and counseling is more effective than counseling alone at preventing relapse..$^{28}$ The retention rate for treatment with medication is greater than the retention rate for medication-free treatment. ${ }^{29}$ Unfortunately, all medications for treating opioid dependence are underutilized by dependent individuals, under-prescribed by physicians, rarely available within in-patient rehabilitation centers, ${ }^{30}$ and rarely used within prisons or drug courts. ${ }^{31}$ According to the Huffington Post, in

maintenance treatment consistently has been demonstrated to reduce drug use and criminal activity among opiate addicts far more effectively than other forms of drug-free outpatient therapy."); Lauren Amato et al., An Overview of Systematic Reviews of the Effectiveness of Opiate Maintenance Therapies: Available Evidence to Inform Clinical Practice and Research, 28 J. Substance Abuse Treatment 321, 323 (2005); Stephen Magura et al., The Effectiveness of In-Jail Methadone Maintenance, 23 J. DRug Issues 75 (1993) (prisoners in a methadone maintenance program were more likely to participate in post-release treatment program, which was associated with lower drug use).

28. See Principles of Drug AdDiCtion, supra note 14, at 10 ("Because they work on different aspects of addiction, combinations of behavioral therapies and medications (when available) generally appear to be more effective than either approach used alone."); Morten Hesse \& Mads Uffe Pederson, Easy-access Services in Low-threshold Opiate Agonist Maintenance, 6 InT'L J. Mental Health AdDiction 316 (2008) (study of combining methadone treatment with counseling in Europe).

29. Sebastian Trautmann \& Hans-Ulrich Wittchen, An Analysis of German Settings Providing Opioid Maintenance Therapy, 47 Substance Use \& Misuse 22, 23 (2012); John R. Caplehorn, A Comparison of AbstinenceOriented and Indefinite Methadone Maintenance Treatment, 29 INT'L J. Addictions 1361 (1994); John R. Caplehorn et al., Clinic Policy and Retention in Methadone Maintenance, 28 InT'L J. ADDICTIONS 73 (1993); Mark L. Willenbring et al., Variations in Evidence-Based Clinical Practices in Nine United States Veterans Administration Opioid Agonist Therapy Clinics, 75 Drug \& Alcohol Dependence 97, 99 (2004).

30. See Cherkis, supra note 16 ("Peer-reviewed data and evidence-based practices do not govern how rehabilitation facilities work.").

31. See Amy Nunn et al., Methadone and Buprenorphine Prescribing and Referral Practices in US Prison Systems: Results from a Nationwide Survey, 105 Drug \& Alcohol DePendence 83, 85; National Association of Drug Court Professionals, Resolution of the Board of Directors on the Availability of Medically Assisted Treatment (M.A.T.) for Addiction in Drug Courts (July 17, 2011), http://www.nadcp.org/sites/default/files/ nadcp/NADCP\%20Board\%20Statement\%20on\%20MAT.pdf; Substance Abuse \& Mental Health Servs. Admin., Adult Drug Courts and Medication-Assisted Treatment for Opioid Dependence, 8 IN BRIEF 4-5 (2014) [hereinafter Adult Drug Courts and Medication-Assisted Treatment for Opioid Dependence]; Drug Courts Help Break Down Barriers to MAT in Criminal Justice System, 22 AlCoHolism \& Drug 
2012 the National Center on Addiction and Substance Abuse at Columbia University published a report that the U.S. treatment system needed "significant overhaul" and suggested that the "low levels of care that addiction patients usually do receive constitutes a form of medical malpractice." ${ }^{32}$

This article focuses on the underuse of one medication in particular, buprenorphine, because it is the most widely used medication for treating opioid dependence ${ }^{33}$ that is cost-effective. ${ }^{34}$ Buprenorphine treatment decreases relapse, ${ }^{35}$ cravings, ${ }^{36}$ mortality, ${ }^{37}$ drug-related crimes, ${ }^{38}$ and Medicaid costs. ${ }^{39}$ It is a life-saving,

Abuse WeEkly 1, 6 (Nov. 1, 2010); Matusow et al., supra note 12, at 475-76 (approximately half of drug courts forbid the use of M.A.T.).

32. See Cherkis, supra note 16. See also Saxon \& McCarty, supra note 16, at 123 .

33. See Cherkis, supra note 16 .

34. For comparison of buprenorphine to methadone, cf. Paul G. Barnett, Comparison of Costs and Utilization Among Buprenorphine and Methadone Patients, 104 AdDiCTion 982, 989-92 (2009). For cost of Vivitrol, see Join Together Staff, Study Finds Extended Release Naltrexone Can Save Overall Healthcare Costs, PARTNERSHIP FOR DrugFREE KIDS (May 15, 2014), http://www.drugfree.org/jointogether/study-finds-extended-release-naltrexone-can-save-overallhealthcare-costs/; Paul G. Barnett et al., The cost-effectiveness of buprenorphine maintenance therapy for opiate addiction in the United States, 96 AdDiCTION 1267 (2001).

35. See Paul Fudala et al., Office-Based Treatment of Opiate Addiction with a Sublingual-Tablet Formulation of Buprenorphine and Naloxone, 349 NEW ENG. J. MED. 949 (2003).

36. See $i d$.

37. See Amy Gibson et al., Exposure to Opioid Maintenance Treatment Reduces Long-Term Mortality, 103 ADDICTION 462, 465 (2008).

38. See, e.g., Michael S. Gordon et al., Buprenorphine Treatment for Probationers and Parolees, 36 Substance Abuse 217 (2015). Cf. Erol Digiusto et al., Effects of Pharmacotherapies for Opioid Dependence on Participants' Criminal Behavior and Expenditure on Illicit Drugs: An Australian National Evaluation (NEOPD), 39 AUSTL. \& N.Z. J. CRIMINOLOGY 171 (2006) (discussing impact of methadone in lowering criminal activity).

39. Informational Bulletin, Center for Medicaid \& CHIP Services, Medication Assisted Treatment for Substance Use Disorders, 1 (July 11, 2014), http://medicaid.gov/Federal-Policy-Guidance/Downloads/CIB07-11-2014.pdf (citing Walter, L. et al., Medicaid Chemical Dependency Patients in a Commercial Health Plan, 32 J. Behav. Health Servs. \& RES. 253 (2005)). 
essential medicine according to the World Health Organization. ${ }^{40}$ The United Nations has recommended that all nations make buprenorphine treatment widely accessible, especially within prisons. ${ }^{41}$

Surprisingly, utilization of buprenorphine is very low in the U.S., ${ }^{42}$ partly due to restrictions placed on prescribers under the Drug Addiction Treatment Act (DATA) of 2000. ${ }^{43}$ In 2013, Senator Markey introduced the Recovery Enhancement for Addiction Treatment Act (TREAT Act) in the Senate, which would loosen DATA's patient limit restrictions and expand prescribing ability to nurse practitioners and physician assistants. ${ }^{44}$ Even though the bill was strongly supported by the American Medical Association, American Society of Addiction Medicine, and other professional organizations ${ }^{45}$, it received scant media or public attention. ${ }^{46}$ The TREAT Act was reintroduced

40. See WHO Model List of Essential Medicines, WorLd HeAlth ORG. (2013), http://apps.who.int/iris/bitstream/10665/93142/1/ EML_18_eng.pdf?ua=1.

41. See World Health Org., U.N. Off. on Drugs and Crime \& U.N. AIDS, Position Paper: Substitution Maintenance Therapy in the Management of Opioid Dependence and HIV/AIDS Prevention 2 (2004) [hereinafter WHO/UNODC/UNAIDS POSITION PAPER: Substitution MaINTENANCE TheraPy], http://www.unodc.org/ documents/hiv-ids/Position\%20Paper\%20sub.\%20maint.\%20therapy.pdf. See also Andrej Kastelic et Al., Opioid Substitution Treatment in Custodial Settings: A Practical Guide 68 (2008), http://www.unodc.org/documents/hiv-aids/

OST_in_Custodial_Settings.pdf.

42. See Ad Fox et al., I Heard About it from a Friend: Assessing Interest in Buprenorphine Treatment, 35 SubSTANCE Abuse 74, 74 (2014).

43. See, e.g., Letter from Stuart Gitlow, President, American Society of Addiction Medicine, to Senator Edward J. Markey, (June 19, 2014) [hereinafter ASAM Letter], http://www.asam.org/docs/defaultsource/advocacy/letters-and-comments/buprenorphine-expansion-actmarkey-letter.pdf ("We have at our disposal highly effective, FDAapproved pharmacotherapies to treat opioid addiction. Unfortunately, they all come with arbitrary treatment limits that have resoundingly negative effects on treatment access and outcomes.").

44. See Recovery Enhancement for Addiction Treatment Act, S.2645, 113th Cong. (2014).

45. See Press Release, Sen. Ed Markey, Markey Introduces Legislation to Expand Treatment for Heroin and Prescription Drug Addiction (July 23, 2014), http://www.markey.senate.gov/news/press-releases/markeyintroduces-legislation-to-expand-treatment-for-heroin-and-prescriptiondrug-addiction.

46. A Google search by the author on February 9, 2015, did not result in any mainstream newspaper headlines regarding the TREAT Act. 
in 2015 in the Senate (where it is currently in committee $^{47}$ ), and a companion legislation was introduced in 2015 in the House of Representatives (where it is also currently in committee). ${ }^{48}$ Medical professional organizations are once again strongly supporting the TREAT Act. ${ }^{49}$

The article begins in Part II with an overview of the three most effective medicines approved by the Food and Drug Administration (FDA) for treating opioid dependence. The section then compares costs and benefits of buprenorphine relative to methadone and Vivitrol. Part III describes existing legal restrictions placed on buprenorphine prescriptions by the Drug Enforcement Agency and by Congress through the Drug Addiction and Treatment Act of 2000. Part IV discusses general reasons for buprenorphine's underutilization, including legal restrictions, cultural stigma, and cost. ${ }^{50}$ Finally, Part $\mathrm{V}$ analyzes the proposed TREAT Act and suggests ways to further improve it.

\section{Overview of Effective Medications}

The three most effective FDA-approved medications for treating opioid dependence are methadone, Vivitrol, and buprenorphine. ${ }^{51}$ These medications are discussed and compared below.

47. See Major Actions

Recovery Enhancement for Addiction Treatment Act, CONGRESS.GOV (2015), https://www.congress.gov/bill/114th-congress/ senate-bill/1455/all-actions? $q=\{\% 22$ search $\% 22 \% 3 \mathrm{~A}[\% 22 \mathrm{RECOVERY+}$ ENHANCEMENT+FOR+ADDICTION+TREATMENT+ACT+S2645 $\% 22]$ \} \&resultIndex $=2$ (last visited October 20, 2015) ("Read twice and referred to the Committee on Health, Education, Labor, and Pensions.").

48. See

Major

Actions

Recovery Enhancement for Addiction Treatment Act, H.R. 2536, CONGRESS.gOV (2015), available at https://www. congress.gov/bill/114th-congress/house-bill/2536/all-actions?q= $\{\% 22$ search $\% 22 \% 3 \mathrm{~A}[\% 22 \backslash \% 22 \mathrm{hr} 2536 \backslash \% 22 \% 22]\}$ \&resultIndex $=1$.

49. Johanna Zussman-Dobbins, Action Requested: Support the TREAT Act, Am. SoC'Y AdDiction Med. Mag. (June 10, 2015), http://www.asam.org/magazine/read/article/2015/06/10/actionrequested-support-the-treat-act.

50. Matusow et al., supra note 12, at 473-74 ("Despite the demonstrated benefits of agonist therapy (and virtual absence of evidence for the efficacy of stand-alone behavioral interventions), concerns persist. Among these concerns are diversion, risk of overdose, the extended duration of treatment, and limited progress patients may make in achieving other treatment goals such as cessation from non-opioid substance abuse and obtaining gainful employment.").

51. See What are the treatments for heroin addiction?, supra note 20. 


\section{A. Methadone}

Methadone is the oldest FDA-approved medication for treating opioid dependence. ${ }^{52}$ It works by activating the opioid receptor in the brain, called the mu-receptor. ${ }^{53}$ Methadone is a complete mu-agonist, meaning that it completely activates the mu-receptor. ${ }^{54}$ As a result, it prevents cravings for opioids, while allowing an individual to stop using heroin and painkillers without experiencing withdrawal symptoms. ${ }^{55}$ Because methadone has a higher selectivity for the mureceptor than do heroin or painkillers, methadone prevents euphoria or a "high" if a person abuses heroin or painkillers while on methadone treatment. ${ }^{56}$ A person undergoing methadone treatment can function normally and does not feel or appear "high." 57 Methadone treatment has been proven to decrease death rates, relapse, drug-related crimes, HIV/AIDS from shared needles, medical costs, and unemployment..$^{58}$ According to the National Institute on Drug Abuse, every dollar invested in methadone treatment saves society 38 dollars. ${ }^{59}$

Methadone can be dangerous if diverted and improperly used; but most individuals who obtain methadone use it for treatment and do not abuse it. ${ }^{60}$ Because methadone has a high potential for physical and psychological dependence, it is a Schedule II narcotic under the Controlled Substances Act (CSA), where Schedule I is the most legally restrictive and Schedule $\mathrm{V}$ is the least restrictive. ${ }^{61}$ In order to prevent illicit diversion, methadone is only available at certified methadone treatment centers, to which the patient must usually return daily in order to continue treatment. ${ }^{62}$ These treatment

52. See generally Joseph Herman et al., Methadone Maintenance Treatment (MMT): A Review of Historical and Clinical Issues. 67 Mount Sinai J. MED. 347, 348 (2000).

53. See generally MedicAtion-Assisted Treatment For Opioid ADDICTION, supra note 27, at 28.

54. See id.

55. Id.

56. See id.

57. See Herman et al., supra note 52, at 361 .

58. Hearing on Heroin and Prescription Drug Abuse, supra note 5.

59. See id.

60. See Herman et al., supra note 52, at 354 .

61. See 21 U.S.C. $\S 813$.

62. See 42 C.F.R. 8.12 (h)-(j). If the patient has continuously undergone methadone maintenance treatment for a period of time and has met the "take-home" eligibility criteria in the D.E.A. regulation, then the methadone clinic may permit him or her to take some methadone home. 
Health Matrix · Volume $26 \cdot$ Issue $1 \cdot 2016$

America Needs the TREAT Act:

Expanding Access to Effective Medication for Treating Addiction

centers are often heavily visible and stigmatized by city governments and residents. ${ }^{63}$

\section{B. Vivitrol}

Vivitrol is a medication for treating both opioid dependence and alcoholism. ${ }^{64}$ Vivitrol does not contain any opioid. ${ }^{65}$ Instead, it contains extended-release naltrexone, which is a complete mu-receptor antagonist, meaning it completely blocks the mu-receptor. ${ }^{66}$ As a result, Vivitrol prevents an individual from experiencing euphoria if he or she abuses any opioid,$^{67}$ making the medication very effective at preventing opioid abuse relapse. ${ }^{68}$

If a patient is given Vivitrol before an opioid has been naturally flushed out of his or her system, then the individual will experience immediate and painful withdrawals. ${ }^{69}$ As a result, opioid addicts must first detox completely before taking Vivitrol. ${ }^{70}$

Vivitrol is not a controlled substance, so it can be prescribed by any physician. ${ }^{71}$ The medicine is taken as a once-per-month injection that lasts for 30 days. $^{72}$ Unfortunately, it is very expensive, costing around $\$ 1,000$ per month for an individual who lacks health insurance coverage, ${ }^{73}$ which is a common scenario for people suffering from substance abuse disorder. ${ }^{74}$

The take-home amount ranges from one day's worth to one monthworth if the patient has been in treatment for at least two years $I d$. at 8.12 (i) (3).

63. See, e.g., Cherkis, supra note 16; Herman et al., supra note 52.

64. See Adult Drug Courts and Medication-Assisted Treatment for Opioid Dependence, supra note 31, at 4-5; Substance Abuse \& Mental Health Servs. Admin., An Introduction to Extended-Release Injectable Naltrexone for the Treatment of People with Opioid Dependence, 11 ADVISORY (2012) [hereinafter An Introduction to Extended-Release Injectable Naltrexone], https://store.samhsa.gov/shin/content/SMA124682/SMA12-4682.pdf.

65. See id.

66. See $i d$.

67. See Adult Drug Courts and Medication-Assisted Treatment for Opioid Dependence, supra note 31.

68. See id.

69. An Introduction to Extended-Release Injectable Naltrexone, supra note 64 .

70. See id.

71. See id

72. See id.

73. See Am. Ass'n for the Treatment of Opioid Dependence, AAOTD Guidelines FOR Using NALtRexone (Vivitrol) in OTPS (2015), 


\section{Buprenorphine}

Buprenorphine is a partial mu-agonist. ${ }^{75}$ As a partial mu-agonist, buprenorphine prevents the opioid-dependent individual from going into withdrawals or experiencing cravings. $^{76}$ Unlike methadone, the opioid in buprenorphine is not very potent, so it is less likely to be abused and rarely causes an overdose. ${ }^{77}$ An individual taking buprenorphine can feel, act, and appear completely normal. ${ }^{78}$

As a partial mu-antagonist, buprenorphine blocks the remainder of the mu-receptor, preventing a "high" from any additional opioid used (including too much buprenorphine). ${ }^{79}$ As a result, individuals who take buprenorphine daily have little incentive to abuse heroin, painkillers, or other opioids.

Buprenorphine can be prescribed at any physician's office, as long as the physician obeys Drug Enforcement Agency (DEA) rules for Schedule III substances, and provided that doctor has a waiver from the Substance Abuse and Mental Health Services Administration (SAMHSA), as required under the Drug Addiction and Treatment Act of $2000{ }^{80}$ An individual undergoing buprenorphine treatment typically receives a monthly prescription, which he or she fills at a local pharmacy, and then takes one or two pills or sublingual films at home daily. ${ }^{81}$ The DEA limits automatic refills on Schedule III narcotics to 5 refills or 6 months (whichever comes first). ${ }^{82}$ However,

http://www.aatod.org/policies/policy-statements/aatod-guidelines-forusing-naltrexone-vivitrol-in-otps/; Walter Armstrong, A Shot in the Dark: Can Vivitrol Help us Control Our Addictions, PAC. Standard MAG. (May 7, 2013), http://www.psmag.com/health-andbehavior/vivitrol-help-control-addictions-57261.

74. Approximately $25 \%$ of drug addicts lack health insurance. See Health Care Overhaul Will Add Coverage for Millions of Addicts, CRAIN's Chicago Bus. (Sept. 11, 2013), http://www.chicagobusiness.com/ article/20130911/NEWS03/130919947/health-care-overhaul-will-addcoverage-for-millions-of-addicts.

75. See generally About Buprenorphine Treatment, U.S. DeP'T OF Health \& HUMAN SERVS., http://buprenorphine.samhsa.gov/about.html.

76. See id.

77. See $i d$.

78. See U.S. DeP'T of Health \& Human Servs., The Facts About Buprenorphine FOR TREATMENT OF AdDiction 3 (2011), http://store.samhsa.gov/shin/content/SMA09-4442/SMA09-4442.pdf.

79. See id.

80. See id. at 4 .

81. See About Buprenorphine Treatment, supra note 75.

82. See 21 C.F.R. § 1306.22. 
physicians commonly require patients on buprenorphine treatment to return monthly for an appointment to obtain a new prescription. ${ }^{83}$

The effectiveness of buprenorphine at preventing relapse, euphoria, and drug cravings has been documented in numerous studies. ${ }^{84}$ When access to buprenorphine increases, mortality from opioid overdose decreases. ${ }^{85}$ For example, in France, increased use of buprenorphine was associated with an $80 \%$ decrease in opioid overdoses. ${ }^{86}$ Additionally, buprenorphine lowers medical costs by preventing the need for expensive in-patient treatment or emergency room visits, increases employment among substance abusers, and reduces drug-related crimes. $^{87}$ Buprenorphine has been used effectively and safely in opioid-dependent pregnant women ${ }^{88}$ and

83. 15 Ways to Save Money on buprenorphine Treatment, NAT'L ALL. Advocates For Buprenorphine Treatment (Dec. 2014), http://www.naabt.org/buprenorphine-cost.cfm ("As the patient stabilizes, s/he can request to have less frequent office visits. Although physicians commonly require patients to come in for appointments every month to monitor the patient's progress, schedule III medications can be refilled up to 5 times in a 6 month period. Visit frequency is ultimately determined by the physician, but it doesn't hurt to ask, particularly for those stable in long-term addiction remission and those who get therapy or counseling from other sources. Some states however, overrule the physician's judgment and have set minimum periods between office visits.").

84. See Declan Barry et al., Integrating Buprenorphine Treatment into Office-based Practice: A Qualitative Study, 24 J. Gen. InTERn. Med. 218, 219 (2009).

85. See CDC, Buprenorphine Prescribing Practices and Exposures Reported to a Poison Center -Utah 2002-2011, 61 Morbidity \& Mortality WEEKLy REPORT 997, 997 (Dec. 14, 2012) [hereinafter CDC, Buprenorphine Prescribing Practices], http://www.cdc.gov/mmwr/ preview/mmwrhtml/mm6149a1.htm ("In France, widespread use of medication-assisted therapy, primarily buprenorphine treatment, was associated with an $80 \%$ decrease in overdose deaths from heroin or cocaine from 465 in 1996 to 89 in 2003"). See also Julien Emmanuelli \& Jean-Claude Desenclos, Harm reduction interventions, behaviours and associated health outcomes in France, 1996-2003, 100 ADDICTION 1690 (2005).

86. See CDC, Buprenorphine Prescribing Practices, supra note 85.

87. See generally Amine Khemiri et al., Analysis Of Buprenorphine/Nalexone Dosing Impact on Treatment Duration, Resource Use, and Costs in the Treatment of Opioid Dependent Adults: A Retrospective Study of U.S. Public and Private Health Care Claims, 126 Postgraduate Med. J. 113 (2014).

88. See Lori Whitten, Buprenorphine During Pregnancy Reduces Neonate Distress, NAT'L INST. ON DRUG ABUSE (July 6, 2012), http://www.drugabuse.gov/news/events/nidanotes/2012/07/buprenorph ine-during-pregnancy-reduces-neonate-distress. 
adolescents. ${ }^{89}$ As the dose of buprenorphine and length of treatment increases, the risk of relapse decreases. ${ }^{90}$ Buprenorphine increases compliance with mental health therapy regimens. ${ }^{91}$ Individuals undergoing buprenorphine treatment are more likely to actively participate regularly in out-patient mental health counseling than individuals who are not undergoing buprenorphine treatment. ${ }^{92}$ Individuals may have an easier time focusing on behavioral and psychological changes if their physical symptoms are controlled.

In 2008, buprenorphine prescriptions cost about $\$ 120-\$ 570$ per month (depending on the dose) without health insurance. ${ }^{93}$ However, the FDA recently approved two generic versions of Suboxone (buprenorphine-nalexone), so the cost of buprenorphine prescriptions for patients may have decreased. ${ }^{94}$ Commercial health insurance carriers ${ }^{95}$ and state Medicaid programs cover buprenorphine treatment (although some Medicaid programs have coverage time limits) ${ }^{96}$. Some pharmaceutical companies that manufacture buprenorphine

89. See Lori Whitten, Youth Opioid Abusers Benefit from Extended Buprenorphine-Nalexone Treatment, NAT'L Inst. ON DRUG Abuse (April 1, 2010), http://www.drugabuse.gov/news-events/nidanotes/2010/04/young-opioid-abusers-benefit-extended-buprenorphinenaloxone-treatment.

90. See George E. Woody et al., Extended vs Short-Term BuprenorphineNaloxone for Treatment of Opioid-Addicted Youth: A Randomized Trial, 300 JAMA 2003, 2007 (2008).

91. See Ryan Caldiero et al., Inpatient Initiation of Buprenorphine Maintenance vs. Detoxification: Can Retention of Opioid-Dependent Patients in Outpatient Counseling be Improved?, 15 AM. J. ON AdDictions 1, 4-6 (2006) (maintenance treatment on buprenorphine leads to higher retention in outpatient counseling than detoxification treatment only).

92. See id. at 4-5.

93. See Lynn E. Sullivan \& David A. Fiellin, Office-Based Buprenorphine for Patients with Opioid Dependence, 148 AnNals of InTERnal Med. 662, 667 (2008).

94. See Paul Jarvis \& Matthew Boyle, Reckitt Benckiser Faces Generic Threats after FDA Rejection, BlOOMBERG Bus. (Feb. 25, 2013), http://www.bloomberg.com/news/articles/2013-02-25/reckitt-benckisersays-fda-rejects-suboxone-safeguard-petition.

95. See Does Insurance Cover It?, NAT'L All. AdvocAtes FOR BuPRENORPHINE TREATMENT (Dec. http://www.naabt.org/faq_answers.cfm?ID $=37$.

96. See Robin Clark et al., The Evidence Doesn't Justify Steps By State Medicaid Programs to Restrict Opioid Addiction Treatment with Buprenorphine, 30 HeALth AFF. 1425, 1425 (2011). 
provide discount cards for low-income individuals, which may eliminate some of the prescription cost. ${ }^{97}$

Probuphine, a slow-release, surgical implant of buprenorphine completed stage III clinical trials in 2015. In January 2016, the Psychopharmacologic Drugs Advisory Committee of the FDA recommended approval of Probuphine. ${ }^{98}$ If approved by the FDA, Probuphine would eliminate the need for frequent doctor visits because the implant would last for 6 months at a time. ${ }^{99}$ The implant would also eliminate the potential for diversion. ${ }^{100}$ It is unclear how and whether current regulations on buprenorphine prescriptions would apply to Probuphine, if approved.

\section{Buprenorphine versus Vivitrol}

Benefits of buprenorphine relative to Vivitrol include the following. Unlike Vivitrol, buprenorphine treatment does not require complete detoxification prior to the first dose. ${ }^{101}$ Rather, buprenorphine treatment begins when the patient is in midwithdrawal. ${ }^{102}$ For many opioid-dependent individuals, the need to completely physically detoxify prior to treatment may act as a disincentive to beginning treatment. Opioid withdrawals are very painful and commonly include multiple days (sometimes weeks) of diarrhea, muscle aches, excessive sweating, jerking or twitching

97. See, e.g., Savings Card May Help Reduce Costs Each Month for Eligible Patients, Suboxone (2014), http://www.suboxone.com/hcp/savingscard.

98. See Titan Pharmaceuticals and Braeburn Pharmaceuticals Announce FDA Advisory Committee Recommends Approval of Probuphine, First 6-Month Implant to Treat Opioid Addiction, Braeburn Pharmaceuticals (Jan. 12, 2016), https://braeburnpharmaceuticals.com/titanpharmaceuticals-and-braeburn-pharmaceuticals-announce-fda-advisorycommittee-recommends-approval-of-probuphine-first-6-month-implantto-treat-opioid-addiction/; Sabrina Tavernise, Implant for Opioid Addicts Urged for Federal Approval, New York Times (Jan. 12, 2016), http://www.nytimes.com/2016/01/13/health/implant-for-opioid-addictsurged-for-federal-approval.html?_r $=0$.

99. $I d$.

100. Id.

101. For information regarding beginning buprenorphine, see Kathleen Thompson-Gargano, What is Buprenorphine Treatment Like?, NAT'L All. Advocates For Buprenorphine Treatment, http://www.naabt.org/education/what_bt_like.cfm. For information regarding beginning Vivitrol, see An Introduction to Extended-Release Injectable Naltrexone, supra note 64.

102. See What is Buprenorphine Treatment Like?, supra note 101. 
muscles, fatigue, and nausea. ${ }^{103}$ Complete detoxification from opioids without relapse is extremely difficult, often requiring multiple attempts. As a result, individuals sometimes enroll in in-patient rehabilitation centers in order to detox, which cost approximately $\$ 31,500$ for 30 days. $^{104}$

Buprenorphine is significantly less expensive than Vivitrol. Brand-name buprenorphine costs approximately $\$ 120-\$ 570$ per month without health insurance, ${ }^{105}$ whereas Vivitrol costs about $\$ 1000$ per month without health insurance. ${ }^{106}$ Also, whereas a patient may obtain up to five automatic refills of buprenorphine without returning to the physician's office, ${ }^{107}$ Vivitrol requires a monthly visit to a physician. ${ }^{108}$ Therefore, aggregate costs associated with physician visits may be higher for a patient treated with Vivitrol.

There are some benefits of Vivitrol relative to buprenorphine. First, unlike buprenorphine, Vivitrol is not a controlled substance, so any physician may legally prescribe it. ${ }^{109}$ Therefore, it may be easier for patients to find a physician prescribing Vivitrol than a physician prescribing buprenorphine. ${ }^{110}$ Second, because Vivitrol is a once-permonth injection, patients may find it easier to adhere to Vivitrol treatment. On the other hand, patients could simply stop taking buprenorphine on any day of the month, because it is a daily pill or sublingual film. ${ }^{111}$ Finally, because Vivitrol contains no opioid ingredient, it is practically impossible to abuse or overdose on Vivitrol. ${ }^{112}$

\section{E. Buprenorphine versus Methadone}

Buprenorphine treatment has several advantages relative to methadone treatment for opioid addiction. First, buprenorphine is less likely to be abused than methadone, because it is a partial mu-agonist

103. See What is withdrawal?, NAT'L All. Advocates For Buprenorphine Treatment (2008), http://www.naabt.org/faq_answers.cfm?ID=16.

104. See Cherkis, supra note 16.

105. See Sullivan \& Fiellin, supra note 93, at 667.

106. See Am. Ass'n for the Treatment of Opioid Dependence, supra note 73; Armstrong, supra note 73.

107. See 21 C.F.R. $\S 1306.22$.

108. See An Introduction to Extended-Release Injectable Naltrexone, supra note 64 .

109. See id.

110. For legal restrictions on prescribing buprenorphine, see supra Part IV.

111. See id.

112. See id. 
rather than a complete mu-agonist. ${ }^{113}$ The opioid ingredient in buprenorphine is less potent than the opioid ingredient in methadone. ${ }^{114}$ As a result, far fewer emergency room visits have been reported from buprenorphine abuse than from methadone abuse. ${ }^{115}$

As compared to methadone, buprenorphine may have less cultural stigma attached to it, because buprenorphine can be prescribed in a physician's office and taken at home daily, potentially making buprenorphine seem like any other medicine. ${ }^{116}$ Furthermore, because buprenorphine may be prescribed by primary care doctors, appointments for buprenorphine treatment seem more anonymous than visiting a methadone clinic. ${ }^{117}$ For example, if a person undergoing buprenorphine treatment is seen entering a primary care doctor's office by a co-worker, then the co-worker has no way of knowing the reason for the visit. On the other hand, entering a methadone clinic is a sure sign of being drug-dependent.

Finally, buprenorphine treatment is less time-consuming than methadone treatment, because a thirty-day supply of buprenorphine can be obtained from a local pharmacy and then taken at home daily. ${ }^{118}$ On the other hand, methadone treatment generally requires daily travel-time to a methadone clinic. ${ }^{119}$ Many individuals suffering from substance abuse are low-income individuals ${ }^{120}$ for whom it may

113. See About Buprenorphine Treatment, supra note 75 ("Because of its ceiling effect and poor bioavailability, buprenorphine is safer in overdose than opioid full agonists. The maximal effects of buprenorphine appear to occur in the 16-32 mg dose range for sublingual tablets. Higher doses are unlikely to produce greater effects.").

114. See $i d$.

115. See id.

116. See Hayley Pinto et al., The SUMMIT Trial: A Field Comparison of Buprenorphine vs. Methadone Treatment, 39 J. Substance ABusE TREATMENT 340 (2010).

117. See id. See also Alison Knopf, Hoffman Death Shows Need for Methadone and Buprenorphine. AlCoholism \& Drug Abuse Weekly 1, 2-3 (Feb. 10, 2014), http://www.alcoholismdrugabuseweekly.com/marticle-detail/hoffman-death-shows-need-for-methadone-andbuprenorphine.aspx.

118. See generally MedicAtion-Assisted Treatment For Opioid ADDICTION, supra note 27; Stotts et al., supra note 27; A.Y. Walley et al., Methadone Dose, Take Home Status and Hospital Admission among Methadone Maintenance Patients, 6 J. AdDICTION MED. 186 (2002).

119. See $i d$.

120. See Frank Chaloupka et al., Introduction, in The ECONOMIC ANALYSIS of Substance Use and Abuse: An Integration of ECONOMEtrics AND BeHAVIORAL ECONOMIC RESEARCH 10 (Frank Chaloupka et al. eds., 1999). 
Health Matrix · Volume 26 Issue $1 \cdot 2016$

America Needs the TREAT Act:

Expanding Access to Effective Medication for Treating Addiction

be especially difficult to pay for daily transportation to a methadone clinic or to take time off of work to visit a clinic.

\section{Existing Buprenorphine Regulations}

\section{A. Drug Enforcement Agency Scheduling}

Under the Controlled Substances Act (CSA), Congress delegates authority to the Attorney General to place substances or drugs within five schedules of control, with Schedule $\mathrm{V}$ being the least restrictive and Schedule I being the most restrictive. ${ }^{121}$ For example, heroin is in Schedule I and oxycodone is in Schedule II. ${ }^{122}$ The Attorney General's decision must be based on the substance's abuse potential, medical value, safety, and potential for dependency. ${ }^{123}$ In making findings about abuse potential, the Attorney General must consider the following factors regarding the substance: actual or relative potential for abuse; scientific evidence of its pharmacological effect; current scientific knowledge; history and current pattern of abuse; scope, duration, and significance of abuse; risks to public health; psychic or physiological dependence liability; and whether it is an immediate precursor of a substance already scheduled under the CSA. ${ }^{124}$ The Attorney General must consult with the Secretary of Health and Human Services before scheduling the substance. If the Secretary recommends against controlling the drug, then the Attorney General must honor that decision. Finally, rules must be made on the record and adhere to rule making requirements under 5 U.S.C.S. $\S$ $551 .{ }^{125}$

In 1981, the FDA approved the first version of buprenorphine as an injectable, hospital-based pain killer. ${ }^{126}$ In 1985, the Drug Enforcement Agency (DEA) scheduled that version of buprenorphine as a Schedule V narcotic under the CSA. ${ }^{127}$ Schedule V controlled substances have the following characteristics: a lower potential for abuse than substances in Schedule IV; a currently accepted medical use in treatment in the U.S.; and limited potential of physical

121. See 21 U.S.C. $\S 812$.

122. See $i d$.

123. See 21 U.S.C. $\S 811($ a)(1).

124. See id.

125. See id.

126. See Schedules of Controlled Substances, 67 Fed. Reg. 62354, 62354 (codified at 21 C.F.R. pt. 1308) (Oct. 7, 2002).

127. Schedules of Controlled Substances, 50 Fed. Reg. 8104 (Feb. 28, 1985). 
dependence or psychological dependence relative to substances in Schedule IV..$^{128}$

In 2002, after other countries (especially France) had successful experiences with buprenorphine for treating opioid dependence, ${ }^{129}$ the FDA approved buprenorphine for treating opioid dependence under the brand names Suboxone and Subutex. ${ }^{130}$ Suboxone contains an abuse-deterrent ingredient, nalexone, which causes immediate withdrawals if the medication is abused by intravenous injection. ${ }^{131}$ Therefore, Suboxone is even less likely to be abused than Subutex or plain buprenorphine. ${ }^{132}$

Aware that buprenorphine would shortly be approved by the FDA for addiction treatment, in 2002 the DEA rescheduled buprenorphine from Schedule V to Schedule III of the CSA (following a recommendation from the Department of Health and Human Services). ${ }^{133}$ Under the CSA, substances in Schedule III have the following characteristics: a lower potential for abuse than substances in Schedules I and II; a currently accepted medical use in treatment in the U.S.; and the potential for moderate or low physical dependence or high psychological dependence. ${ }^{134}$

According to the National Alliance of Advocates for Buprenorphine Treatment, the DEA rescheduled buprenorphine despite "overwhelming objection from the medical community," which was concerned that more restrictive scheduling would cause accessibility problems. ${ }^{135}$ The American Academy of Addiction Psychiatry and the American Association of Addiction Medicine both recommended less restrictive scheduling for Suboxone, especially because it contains naloxone. ${ }^{136}$

128. See 21 U.S.C. $\S 812$ (b)(5).

129. See CDC, Buprenorphine Prescribing Practices, supra note 85. See also Emmanuelli \& Desenclos, supra note 85, at 1696.

130. Subutex and Suboxone Approved to Treat Opiate Dependence, U.S. FOOD \& DRUG ADMIN. (Oct. 8, 2012), http://www.fda.gov/Drugs/DrugSafety/

PostmarketDrugSafetyInformationforPatientsandProviders/ucm191521.h tm.

131. See 67 Fed. Reg. 62354, 62358 (Oct. 7, 2002).

132. See $i d$.

133. See id. at 62354 .

134. See 21 U.S.C. $\S 812$ (b)(3).

135. Laws, Nat'l All. Advocates for Buprenorphine Treatment (Oct. 29, 2013), http://www.naabt.org/laws.cfm.

136. See generally 67 Fed. Reg. 62354, 62355 (Oct. 7, 2002). 
In its determination of buprenorphine's abuse potential, the DEA considered the fact that buprenorphine would be prescribed to "known drug abusers." 137 In its response to comments on the Final Rule addressing rescheduling, the DEA wrote, "Simply stated, providing an abusable substance to known drug abusers imparts enhanced risks [sic]." ${ }^{38}$

The DEA also feared that buprenorphine would be illicitly obtained by the opioid naïve (new users) or by "non-dependent, opioid-experienced subjects". ${ }^{139}$ The DEA found that such individuals may feel "good drug effects" 140 if they try to abuse buprenorphine. Ironically, opioid-dependent individuals rarely feel any "good drug effects" from buprenorphine. ${ }^{141}$ Instead, they feel normal when treated with buprenorphine. ${ }^{142}$

By rescheduling buprenorphine, the DEA appeared to be more concerned with buprenorphine's potential to harm opioid naïve and non-opioid-dependent individuals than with its potential benefits to opioid-dependent individuals. ${ }^{143}$ In its response to comments on the Final Rule, the DEA stated that "buprenorphine has abuse potential in a wide spectrum of individuals. Vulnerable populations include drug naïve individuals (new drug abusers), opioid experienced individuals and opioid dependent individuals."144 However, later the DEA stated that, "The extent to which buprenorphine is able to produce euphoria and "good drug" effects limits its use by opioid tolerant abusers." $" 145$

The DEA did not worry much about the impact of rescheduling buprenorphine on access to treatment. ${ }^{146}$ In response to a comment that rescheduling buprenorphine would make it less accessible for dependent individuals who need buprenorphine for treatment, the DEA said the following:

137. Id. at 62357 .

138. Id.

139. Id. at 62358 .

140. Id.

141. See id.

142. See The Facts about Buprenorphine for Treatment of Opioid Addiction, supra note 78 , at 3 ; Medication proponents make pitch to drug court professionals, 16 Alcoholism \& Drug Abuse Weekly 2 (Aug. 16, 2004).

143. See 67 Fed. Reg. 62354, 62357-62358.

144. Id.at 62357 .

145. Id. at 62359 .

146. See id. at 62363 . 
The proposed placement of buprenorphine in Schedule III was not made on the basis of making buprenorphine products available for office-based narcotic treatment... The DEA did not consider the need to expand narcotic treatment as a specific factor in determining the placement of buprenorphine under the CSA. $^{147}$

The more restrictive the scheduling, the less accessible the medication becomes. All physicians who prescribe controlled substances must register with the DEA, obtain a DEA number, and meet DEA reporting requirements. ${ }^{148}$ However, under the CSA physicians may only prescribe automatic refills for Schedule III narcotics for up to six months or five prescriptions (whichever is first). ${ }^{149}$ On the other hand, there are no automatic prescription limitations for prescribing Schedule V substances. ${ }^{150}$ Also, the more restrictive the scheduling, the less likely physicians may be to prescribe the medication out of fear of losing their medical license for wrong-doing. ${ }^{151}$

\section{B. Drug Addiction and Treatment Act of 2000}

Foreseeing the likely FDA approval of buprenorphine, Congress passed the Drug Addiction and Treatment Act (DATA) in 2000. DATA modified the CSA, ${ }^{152}$ permitting physicians to prescribe Schedule III, IV, and V substances for addiction treatment, while trying to prevent its diversion and abuse. ${ }^{153}$

147. Id.

148. See 21 U.S.C. $\S 823(\mathrm{~g})$.

149. See 21 C.F.R. $\S 1306.22$.

150. See id.

151. See Rob Stein, Painkiller Paradox: Feds Struggle to Control Drugs that Help and Harm, NPR (Jan. 23, 2013), http://www.npr.org/blogs/health/2013/01/23/169963431/painkillerparadox-feds-struggle-to-control-drugs-that-help-and-harm.

152. See 21 U.S.C. $\S 823(\mathrm{~g})$.

153. See Drug Addiction Treatment Act of 2000, 146 Cong. REC. H6374H6375 (Rep. Gilman said the following: "[The legislation] seeks to assist qualified physicians in treating their addicted patients, to speed up approval of narcotic drugs for addiction treatment purposes, and offers treatment options for those Americans for whom other treatment programs are financially out of reach... The bill contains a number of safeguards that are designed to prevent abuses of the waiver procedure." Id. at H6377). The Drug Addiction Treatment Act was ultimately passed by Congress as Title XXXV, Section 3502 of the Children's Health Act of 2000. 
DATA was passed by Congress with little controversy. The initial version of the Act, DATA of 1999, was introduced by Senator Hatch (R) in the Senate but was never voted upon. ${ }^{154}$ Representative Biley $(\mathrm{R})$ then re-introduced DATA in the House of Representatives with Republican and Democratic co-sponsors as DATA of 2000. ${ }^{155}$ It easily passed in the House with 412 "yea" votes and only one "nay" vote. $^{156}$ The Senate then added DATA of 2000 as an amendment to the Children's Health Act of 2000. ${ }^{157}$ The Senate approved this version of the Children's Health Act unanimously. The revised Children's Health Act returned to the House for a final vote, where it was passed by a large majority ${ }^{158}$ with DATA as Title XXXV. ${ }^{159}$

DATA became law two years prior to the DEA rescheduling buprenorphine from Schedule $\mathrm{V}$ to Schedule III of the CSA. The DEA was aware of DATA and its purpose. However, in its Final Rule the DEA stated that it was not considering how rescheduling buprenorphine would impact the objectives of DATA: "The Drug Addiction Treatment Act (DATA) does not have an impact on DEA's scheduling responsibilities under the CSA."160

DATA requires physicians to obtain a waiver (colloquially called a DATA waiver or SAHMSA waiver) from the Secretary of Health and Human Services. ${ }^{161}$ In order to obtain a waiver, the physician must submit a notification of intent to the Secretary to begin prescribing such medications to the Secretary. This notification must demonstrate that the physician meets the following requirements

154. Drug Addiction Treatment Act of 1999, S. 324, 106th Congress (1999).

155. Drug Addiction Treatment Act of 2000, H.R. 2634, 106th Congress (2000). Representative Bliley (R) was the main sponsor, with the following co-sponsors: Boucher (D), Green (D), Rangel (D), Norwood $(\mathrm{R})$, Upton $(\mathrm{R})$, Coble $(\mathrm{R})$, Greenwood $(\mathrm{R})$, Deal $(\mathrm{R})$, Cox $(\mathrm{R})$, and Oxley (R).

156. See Final Vote Results for Roll Call 416 (Drug Addiction Treatment Act of 2000), OfFice OF THE CleRK OF THE U.S. HOUsE OF REPRESENTATIVES (July 2000). http://clerk.house.gov/evs/2000/roll416.xml.

157. See S.Amdt. 4181 to H.R.4365, 106th Congress (2000).

158. See Final Vote Results for Roll Call 496 (Children's Health Act of 2000), OfFice of the Clerk of the U.S. House of Representatives (Sep. 27, 2000), http://clerk.house.gov/evs/2000/roll496.xml. There were 394 Yea votes and 25 Nay votes.

159. Children's Health Act of 2000, Pub. L. No. 106-310, § 3502, (codified at (g) (2006)).

160. See Schedules of Controlled Substances, 67 Fed. Reg. 62354, 62366 (Oct. 7, 2002).

161. See id. at $\S 823(\mathrm{~g})(2)(\mathrm{A})$. 
under DATA: 1) the physician is "qualified" to prescribe medication for opioid dependence treatment; 2) the physician will adhere to the patient limits in DATA; and 3) the physician has the capacity to refer patients for ancillary mental health services. ${ }^{162}$ DATA's definition of "qualified physician" and patient limits are described below.

\section{Qualified Physicians}

A physician becomes "qualified" by meeting the requirements in section 2(a)(5)(G) of DATA. First, the physician must have a valid medical license under state law. ${ }^{163}$

Second, the physician must prove that he or she has the necessary education or experience to treat opioid-dependent individuals with buprenorphine (and similar medicines). The physician may demonstrate the education/experience requirement in any one of the following ways:

(a) by having been awarded board certification as an addiction specialist (by a major medical authority listed in the statute); or

(b) by completing an addiction medicine educational course at least 8 hours in length (provided by a medical authority listed in the statute); or

(c) by participating as a principal investigator in a drug trial for buprenorphine or a similar medication; or

(d) by otherwise convincing the state's medical board or the U.S. Secretary of Health that the physician has valid experience/education for treating opioid-dependent patients. ${ }^{164}$

Physician assistants and nurse practitioners cannot become qualified (cannot obtain a DATA waiver), even if they are licensed in a state that permits physician assistants and nurse practitioners to prescribe Schedule III, IV, or V medications. ${ }^{165}$

\section{Patient Limits}

In addition to defining who constitutes a "qualified physician" for purposes of obtaining a DATA waiver, DATA also places restrictions on the number of patients a qualified physician may treat at any one time. ${ }^{166}$ These patient restrictions have been widely criticized within

162. Id.

163. Id.

164. Id. at $\S 823(\mathrm{~g})(2)(\mathrm{B})(\mathrm{iii})$.

165. See id. at $\S 823(\mathrm{~g})(2)(\mathrm{G})$.

166. See id. at $\S 823(\mathrm{~g})(2)(\mathrm{B})(\mathrm{iii})$. 
the medical community. ${ }^{167}$ Since the passage of DATA, Congress has twice amended the patient restrictions in order to expand the number of patients a physician may treat. ${ }^{168}$

\section{a. Original Patient Limits}

The original DATA Act prohibited any physician from treating more than thirty patients with buprenorphine at any time. ${ }^{169}$ The original DATA Act also prohibited a group practice of physicians from treating more than thirty patients with buprenorphine at any time. ${ }^{170}$ In other words, if three physicians owned a group practice and one of those physicians was treating thirty patients with buprenorphine, then the other two physicians could not treat any patients with buprenorphine.

\section{b. 2005 Amendment}

In 2005, Congress passed the Drug Addiction Treatment Expansion Act, which amended DATA by eliminating the thirty patient limit on group practices, but leaving the thirty patient limit in place for each qualified physician. ${ }^{171}$ Under this law, if three physicians owned a group practice, then each physician within the group could treat up to thirty patients at any time with buprenorphine. ${ }^{172}$

The legislative history of the Drug Addiction Treatment Expansion Act demonstrates that Congress was concerned with the negative effects that the group prescription limit had on patient access. Rep. Mark Souder made the following statement regarding the need for the Drug Addiction Treatment Expansion Act:

167. See, e.g., ASAM Letter, supra note 43 ("We have at our disposal highly effective, FDA-approved pharmacotherapies to treat opioid addiction. Unfortunately, they all come with arbitrary treatment limits that have resoundingly negative effects on treatment access and outcomes."); Medication-Assisted TREATMENT FOR OpIOID ADdiction, supra note 27, at 4-5 (noting that a National Institute of Health consensus panel has called for less restrictions on medication for treating addiction).

168. See Drug Addiction Treatment Expansion Act, 151 Cong. ReC. D877 (daily ed. Sept. 6, 2005); Office of National Drug Control Policy Reauthorization Act of 2006, Public L. 109-469 (2006) (codified at 21 U.S.C. $\S 1701$, et seq.)

169. See Drug Addiction Treatment Act of 2000, 21 U.S.C. $\S 823$ (g) (2)(B)(iii).

170. See id.

171. See Drug Addiction Treatment Expansion Act, 21 U.S.C. $\S 823$ $(\mathrm{g})(2)(\mathrm{B})$.

172. See id. 
Health Matrix · Volume $26 \cdot$ Issue $1 \cdot 2016$

America Needs the TREAT Act:

Expanding Access to Effective Medication for Treating Addiction

According to the American Medical Association, the current 30patient cap has limited access to effective substance abuse treatment services...Lifting the cap would enable group practices to treat more patients with this highly effective drug. ${ }^{173}$

\section{c. 2006 Amendment}

In 2006, due to growing demand for buprenorphine and long wait times to see qualified physicians, Congress passed the Office of National Drug Control Policy Reauthorization Act. ${ }^{174}$ This is the current law with respect to patient limits. Title XI of the Act permits physicians who have had a DATA waiver for at least one year to treat up to 100 patients beginning the second year, after notifying the Health Secretary of their intent to treat 100 patients. ${ }^{175}$ When the Act passed, Sen. Orin Hatch made a congratulatory speech:

It is clear this [30 patient] cap needs to be raised. To make an analogy, a doctor who would not turn away a broken arm because he or she had already fixed 30 arms that month! The doctor would not stand for it, and neither would society. The same should be true for physicians treating drug addiction. Given that the destructive effects of drug addiction are so much greater than a broken arm, we should strive to ensure that the healing hands of doctors are not bound by unintended mandates. ${ }^{176}$

\section{UNDERUSE OF BUPRENORPHINE}

Despite buprenorphine's benefits, it is still underutilized. The U.S. Substance Abuse and Mental Health Services Administration, ${ }^{177}$ the American Medical Association, ${ }^{178}$ the American Society of

173. 151 Cong. REC. H6679-H6681 (daily ed. July 27, 2005) (Statement of Rep. Souder).

174. See Office of National Drug Control Policy Reauthorization Act of 2006, Public L. 109-469 (2006).

175. See id.

176. 152 Cong. ReC. S11703-S11706 (daily ed. Dec. 8, 2006) (statement of Sen. Orin Hatch).

177. See, e.g., Adult Drug Courts and Medication-Assisted Treatment for Opioid Dependence, supra note 31.

178. Statement of the American Medical Association to the Committee on Energy 85 Commerce Subcommittee on Oversight and Investigations, U.S. House of Representatives at 6, (April 23, 2015), http://docs.house.gov/meetings/IF/IF02/20150423/103367/HHRG-114IF02-Wstate-HarrisP-20150423.pdf. 
Addiction Medicine, ${ }^{179}$ and the World Health Organization ${ }^{180}$ all agree that buprenorphine treatment should be more widely used to treat opioid addiction. In order to encourage utilization of buprenorphine for addiction treatment, policy makers should address reasons for its underuse. Scholars have reported the following reasons for underuse: cultural bias against MAT (medication assisted treatment for drug dependence); bias from NA and other 12-step groups; bias among mental health therapists; an undersupply of physicians with a DATA waiver; patient limits under DATA; cost; and concerns of illicit diversion.

\section{A. Cultural Bias Against MAT}

The U.S. has an unusual cultural bias against the use of FDAapproved medication for treating drug dependence, ${ }^{181}$ especially given the fact that medication is commonly used to treat other illnesses. Americans consider pharmaceuticals to be a normal part of life, as the frequency of television advertisements for pharmaceuticals demonstrates. Then, why is medication for treating drug dependence so heavily stigmatized?

Bias against MAT likely stems from America's historical paradigm of treatment for drug dependence, which has been "abstinence-only" (usually meaning without medications containing an opioid ingredient). Today, abstinence-only treatment is the norm in the U.S. and is deeply entrenched in U.S. culture. ${ }^{182}$ Abstinenceonly treatment is espoused by NA, AA and other twelve-step groups. ${ }^{183}$ Twelve-step programs are the predominant form of treatment within U.S. prisons, drug courts, and in-patient rehabilitation centers. ${ }^{184}$ NA also has a powerful influence on the treatment methods of many mental health counselors. ${ }^{185}$ Therefore, to

179. ASAM Letter, supra note 43 ("We have at our disposal highly effective, FDA-approved pharmacotherapies to treat opioid addiction. Unfortunately, they all come with arbitrary treatment limits that have resoundingly negative effects on treatment access and outcomes.")

180. See WHO Model List of Essential Medicines, supra note 40; WHO/UNODC/UNAIDS Position PAPER: Substitution Maintenance THERAPY, supra note 41.

181. See generally MedicAtion-Assisted Treatment For Opioid ADDICTION, supra note 27, at 8-10.

182. See Cherkis, supra note 16.

183. See $i d$.

184. See id.; Emily Galas, Endorsing Religion: Drug Courts and the 12-Step Recovery Support Program, 53 Am. U. L. REV. 1063, 1070 (2004); Nunn et al., supra note 31 , at 87 . 
Health Matrix · Volume 26 Issue $1 \cdot 2016$

America Needs the TREAT Act:

Expanding Access to Effective Medication for Treating Addiction

understand America's attitudes towards drug dependence treatment, one must understand the philosophy of NA.

$\mathrm{NA}$ is a derivative of $\mathrm{AA}$ and operates in an identical manner to $\mathrm{AA}$, except that members of NA are usually drug-dependent, while members of AA are alcohol-dependent. In brief, members of NA attend group meetings regularly, follow twelve steps of treatment, and receive emotional support and guidance from a sponsor within the group. ${ }^{186}$ AA originated from an evangelical, Protestant church in the 1930s called the Oxford Group. ${ }^{187}$ Bill W., a member of the Oxford Group started AA to share with others the way he became sober. He became sober after a spiritual experience, ${ }^{188}$ which convinced him that any chemical-dependent individual can overcome his or her dependence through a similar spiritual experience. He believed that sobriety can be achieved if the individuals shifts his or her dependence away from chemicals and towards a Higher Power. ${ }^{189}$ He also believed that chemical-dependent individuals (mainly alcoholics) must support each other on their journey of recovery through fellowship meetings. ${ }^{190}$ Based off of these principles, Bill W. developed the following 12 steps (adopted by NA) that one must undergo in order to recover from chemical dependence: ${ }^{191}$

1. We admitted that we were powerless over our addiction, that our lives had become unmanageable.

2. We came to believe that a Power greater than ourselves could restore us to sanity.

3. We made a decision to turn our will and our lives over to the care of God as we understood Him.

185. See Traci Rieckmann et al., A Multi-level Analysis of Counselor Attitudes Toward the use of Buprenorphine in Substance Abuse Treatment, 41 J. of Substance Abuse Treatment 374 (2011). See also Hannah Knudsen et al., Buprenorphine Diffusion: The Attitudes of Substance Abuse Treatment Counselors, 29 J. Substance ABuse TREATMEnt 95 (2005).

186. See generally Galas, supra note 184 .

187. See id. at 1073.

188. See $i d$.

189. See id. at 1074.

190. See id. at 1074-75.

191. How it Works, NARCOTICS ANONYMous, http://www.na.org/admin/ include/spaw2/uploads/pdf/litfiles/us_english/misc/How\%20it\%20Wor ks.pdf. 
Health Matrix · Volume 26 Issue $1 \cdot 2016$

America Needs the TREAT Act:

Expanding Access to Effective Medication for Treating Addiction

4. We made a searching and fearless moral inventory of ourselves.

5. We admitted to God, to ourselves, and to another human being the exact nature of our wrongs.

6. We were entirely ready to have God remove all these defects of character.

7. We humbly asked Him to remove our shortcomings.

8. We made a list of all persons we had harmed and became willing to make amends to them all.

9. We made direct amends to such people wherever possible, except when to do so would injure them or others.

10. We continued to take personal inventory and when we were wrong promptly admitted it.

11. We sought through prayer and meditation to improve our conscious contact with God as we understood Him, praying only for knowledge of His will for us and the power to carry that out.

12. Having had a spiritual awakening as a result of these steps, we tried to carry this message to addicts, and to practice these principles in all our affairs. ${ }^{192}$

The twelve steps have the following themes: regular communication with the group, dependence on a Higher Power, striving for moral purity, seeking forgiveness, helping others stay drug-free, and admitting the nature of one's problem. ${ }^{193}$ NA and AA identify alcoholism and drug dependence as a disease, not as a moral failing, but the treatment hinges on spiritual and moral steps. ${ }^{194}$ Medication, on the other hand, is unrelated to spiritual healing, and thus does not fit neatly into the discourse of NA or AA.

Even though most Americans are not dependent on opioids and have little education about its treatment, many Americans assume that NA/AA or a similar twelve-step group is the best treatment for opioid dependence. ${ }^{195}$ The belief is so common that it even pervades

192. See id.

193. See id.

194. See id.

195. See generally Cherkis, supra note 16 . 
offices of some health care practitioners. ${ }^{196}$ For example, most inpatient rehabilitation centers ${ }^{197}$ and a large minority of mental health counselors believe that NA/AA alone or with counseling is the best form of treatment for opioid dependence. ${ }^{198}$ This belief has also infiltrated the criminal justice system. Drug courts routinely require that drug offenders attend an NA or AA meeting daily, ${ }^{199}$ but only half allow the use of MAT. ${ }^{200}$ Likewise, few prison clinics offer MAT. ${ }^{201}$

Within the cultural context of NA, medication for treating drug dependence does not sit well with the abstinence-oriented ideas of many Americans. ${ }^{202}$ Additionally, the provision of medication that contains an opioid ingredient to known drug abusers strikes some Americans as being "immoral," despite the medications' effectiveness at lowering crime rates, mortality, morbidity, and medical costs. For example, despite the proven benefits of methadone, in the 1990s New York City then-Mayor Rudy Guiliani called methadone treatment an "immoral solution" to opioid dependence. ${ }^{203}$

Many Americans assume that drug dependence is caused by being an immoral person. ${ }^{204}$ Therefore, treating dependence seems to require the provision of morality, not medication. NA fits comfortably within this idea of morality-induced abstinence. Even though NA officially calls addiction a disease, NA requires the addict to seek forgiveness, to strive for moral purity, and to forge a relationship with a Higher Power. ${ }^{205}$ Obtaining a prescription for medication from a physician,

196. See John F. Kelly, Self-Help for Substance-Use Disorders: History, Effectiveness, Knowledge Gaps, and Research Opportunities, 23 Clinical Psychology Rev. 639, 642-43 (2003).

197. See, e.g., Cherkis, supra note 16.

198. See Knudsen et al., supra note 185, at 98.

199. See, e.g., Jennifer Murphy, Drug Court as Both a Legal and Medical Authority, 32 Deviant Behav. 257, 270-71 (2011); Galas, supra note 184 , at 1074 .

200. See Alison Knopf, NADCP supports MAT but questions lack of medication protocols, Alcoholism \& Drug ABuSe WeEKly (July 21, 2014), http://www.alcoholismdrugabuseweekly.com/m-articledetail/nadcp-supports-mat-but-questions-lack-of-medicationprotocols.aspx.

201. See id.

202. See Cherkis, supra note 16.

203. See id.

204. See generally Matthew Stanbrook, Addiction is a Disease: We Must Change Our Attitudes Towards Addicts, 184 Canadian Med. Ass. J. 155, 155 (2012).

205. See Murphy, supra note 199; Galas, supra note 184, at 1074-75. 
on the other hand, does not require seeking forgiveness, making amends, or developing any kind of spirituality. NA's focus on morality also makes it particularly attractive to criminal justice administrators, including drug court judges, who are trying to reform "criminals."

NA (through its headquarters) has not officially taken a position against MAT. ${ }^{206}$ However, according to the main website of NA, individual NA groups are permitted to decide whether or not to ban participants who use MAT from attending meetings. ${ }^{207}$ Not surprisingly, published studies report that some members of NA and similar twelve-step groups feel stigmatized if they use MAT. ${ }^{208}$ For example, these members report not telling their sponsors about their medical treatment, because sponsors might misunderstand it as substituting one chemical addiction for another. ${ }^{209}$ NA and similar groups are also unlikely to educate members about the existence of buprenorphine and other forms of MAT. ${ }^{210}$ Therefore, NA contributes to the underuse of buprenorphine: indirectly through the cultural norm of abstinence-only treatment, and directly (in some groups) by preventing MAT patients from attending meetings. ${ }^{211}$

\section{B. Effects of the War on Drugs}

The War on Drugs contributes to the underuse of buprenorphine in two ways: by stigmatizing drug-dependent individuals and by causing them to hide their illness (rather than seeking treatment) out

206. See NA Groups and Medication, NARCOTICS ANONYMous (2007), http://www.na.org/admin/include/spaw2/uploads/pdf/servicemat/Dec2 011_NA_Groups_and_Medication.pdf.

207. See $i d$.

208. See William White, NARCotics Anonymous AND the Pharmacotherapeutic Treatment of Opioid AdDiction in the United States 24, 44-45, 53(2011).

209. See id. at 26-27. See also Hearing on Heroin and Prescription Drug Abuse, supra note 5 ("Medication-assisted treatments remain grossly underutilized in many addiction treatment settings, where stigma and negative attitudes (based on the misconception that buprenorphine or methadone "substitute a new addiction for an old one") persist among clinic staff and administrators.").

210. See WHITE, supra note 208, at 22 ("Seen as a whole, NA literature defines the use of medically supervised methadone maintenance and other pharmacotherapies for opioid addiction as differing little from illicit drug use or alcohol use. It asserts that views restricting the participation of NA members on medications like methadone and buprenorphine are means of asserting NA's philosophy of complete abstinence and maintaining the recovery atmosphere of NA meetings.").

211. See id. 
of fear of punishment for drug possession. Since the 1970s, the U.S. has conducted a "War on Drugs," so named by President Nixon. ${ }^{212}$ The War on Drugs is characterized by criminal prosecution of drug possessors and suppliers, with little focus on treatment for drug dependence. ${ }^{213}$ From an economic perspective, it is supply focused rather than demand focused. Unfortunately, the effectiveness of the War on Drugs seems minimal at best according to most political science and criminal justice scholars. ${ }^{214}$

Because drugs are illegal, many people believe that drug dependence itself is immoral. ${ }^{215}$ This misconception is bolstered by the fact that drug dependence is not a defense to a crime of drug possession. $^{216}$ However, medical authorities, such as the American Medical Association, and even NA/AA, have called drug dependence a disease, not a moral failing. ${ }^{217}$ Even if the first episode of drug abuse is voluntary, for many individuals repeated drug abuse becomes physically and psychologically compulsive. ${ }^{218}$ As a result, will-power is usually insufficient to stop addictive behavior. ${ }^{219}$ Unfortunately, the War on Drugs perpetuates the common misconception that drug dependence is a personal choice and a personal failing rather than a disease, because the War on Drugs focuses government resources on prosecution of drug offenders rather than on treatment of dependence. ${ }^{220}$

212. See generally John Cutcliffe \& Belal Saadeh, Grounded in Evidence or a Puritanical Legacy: A Critique of Twenty-First Century U.S. Drug Policy, 7 Mental Health \& Substance Use 195, 195 (2014).

213. See $i d$. at 196.

214. See, e.g., id. at 195.

215. See generally Stanbrook, supra note 204; Jennifer Murphy, Drug Court as Both a Legal and Medical Authority, 32 Deviant Behav. 257, 258 (2011).

216. See United States v. Moore, 486 F.2d 1139, 1147 (D.C. Cir. 1973).

217. See Galas, supra note 184 , at 1074.

218. See generally Steven Hyman \& Robert Malenka, Addiction and the brain: The neurobiology of compulsion and its persistence, 2 NATURE RevieWs Neuroscience 695 (2001).

219. See generally id.

220. See Kalynn Amundson et al., Pathologies of the Poor: What do the War on Drugs and Welfare Reform Have in Common? 41 J. Sociology \& Social Welfare 5, 17 (2014) (A study of rhetoric used in the War on Drugs found, "Most references to drug addiction, in both War on Drugs and Welfare Reform documents, were largely from a punitive criminal justice frame advocating punishment, rather than a medical frame, which views addiction as a medical condition requiring treatment, although there were some mentions of treatment and rehabilitation."). 
The U.S. spends billions of dollars annually on the War on Drugs. ${ }^{221}$ According to the Federal Bureau of Prisons, in December 2014, $48.7 \%$ of individuals in federal prisons were incarcerated for drug offenses. ${ }^{222}$ Incarceration of drug offenders, especially non-violent drug offenders, contributes to the U.S. having the highest incarceration rate in the world. ${ }^{223}$ Incarceration for non-violent drug crimes has especially devastated many African American families and neighborhoods. ${ }^{224}$ Individuals who are convicted of drug possession, including marijuana possession, are ineligible for food stamps, public cash assistance, student educational loans, and (in some states) the use of a driver's license. ${ }^{225}$ Therefore, admission of drug dependence to a doctor or a counselor may strike fear in the heart of many people who do not understand privacy laws, preventing help-seeking behavior.

In this cultural context riddled with misconceptions about drug dependence, the Affordable Care Act has called substance abuse treatment one of the ten essential services that must be offered by expanded Medicaid programs and by insurance on government-run exchanges. ${ }^{226}$ Former U.S. deputy drug czar, A. Thomas McLellan, has said, "There is no illness that will be more favorably affected [by the Affordable Care Act] than substance abuse."227 However, with the

221. See Jeffrey Timberlake et al., How Should We Wage the War on Drugs? Determinants of Public Preferences for Drug Control Alternatives, 31 POL'y STUD. J. 71, 72-73 (2003).

222. Offenses, Fed. Bureau of Prisons (Dec. 27, 2014), http://www.bop.gov/about/statistics/statistics_inmate_offenses.jsp.

223. See Criminal Justice Fact Sheet, NAACP (2015), http://www.naacp.org/pages/criminal-justice-fact-sheet.

224. See Lisa Moore \& Amy Elkavich, Who's Using and Who's Doing Time: Incarceration, The War on Drugs, and Public Health, 98 AM. J. PuB. HEALTH 782, 784 (2008).

225. See U.S. Dep; of Health and Human Servs., Are You in Recovery From Alcohol or Drug AdDiction? Know Your Rights 12-13, https://store.samhsa.gov/shin/content/PHD1091/PHD1091.pdf (last visited Feb. 9, 2015).

226. See Substance Abuse and the Affordable Care Act, Office OF NATIONAL Drug CONTROL POLICY, http://www.whitehouse.gov/ondcp/healthcare (last visited Feb. 9, 2015) ("The ACA includes substance use disorders as one of the ten elements of essential health benefits. This means that all health insurance sold on Health Insurance Exchanges or provided by Medicaid to certain newly eligible adults starting in 2014 must include services for substance use disorders.").

227. Anna Gorman, Barriers Remain Despite Health Law's Push to Expand Access to Substance Abuse Treatment, Kaiser Health News (Apr. 10, 2014), http://kaiserhealthnews.org/news/substance-abuse-treatmentaccess-health-law/. 
ongoing background of the War on Drugs, many Americans may feel confused about whether or not it is "safe" for them to seek treatment for drug dependence. ${ }^{228}$

Finally, the War on Drugs has stigmatized individuals suffering from substance-abuse by labeling them as criminals. Individuals with stigmatized medical problems are particularly likely to hide their medical problems and not seek medical treatment. ${ }^{229}$ Such was the case historically with HIV/AIDS. ${ }^{230}$ Persons with dependence problems do not want their friends, family, and co-workers to think of them as criminals or moral failures. ${ }^{231}$

\section{Undersupply of Doctors with a DATA Waiver}

In 2012, only $46.6 \%$ of U.S. counties had at least one physician with a DATA waiver. ${ }^{232}$ Only $2 \%$ of all U.S. physicians have a DATA waiver, and only $3 \%$ of primary care physicians (the largest group of physicians in the nation) have obtained a DATA waiver. ${ }^{233}$ Even though any physician with a DATA waiver may prescribe buprenorphine, primary care doctors are especially well-positioned to help individuals with substance abuse.

First, a primary care doctor is usually the first doctor with whom a person is able to obtain an appointment. Primary doctors are the "gateway" to medical treatment. ${ }^{234}$ For example, commercial insurance often requires a referral from a primary care doctor before a patient sees a specialist. In some towns, a primary care doctor is the only type of doctor available, because the population size is too small to support specialist physicians. According to one medical study, psychiatrists are the group of physicians most likely to obtain a DATA waiver, yet "they are rare or nonexistent in rural America." 235

228. See Richard C. Rapp et al., Treatment Barriers Identified by Substance Abusers Assessed at Centralized Intake Unit, 30 J. Substance Abuse TREATMENT 227, 228 (2005).

229. $I d$.

230. See Valerie Earnshaw et al., Drug Addiction Stigma in the Context of Methadone Maintenance Therapy: An Investigation into Understudies Sources of Stigma. 11 InT'L. J. Mental Health AdDiction 110, 111-12 (2013).

231. See id., at 111-12.

232. See Roger Rosenblatt et al., Geographic and Specialty Distribution of U.S. Physicians Trained to Treat Opioid Use Disorder, 13 Annals of FAMILY MED. 23, 25 (2015).

233. See id.

234. See generally Leiyu Shi, The Impact of Primary Care: A Focused Review, 2012 SCIENTIFICA 1 (2012).

235. Rosenblatt et al., supra note 232 , at 25 . 
Second, appointment fees to see a primary care doctor are typically lower than those to see a specialist. ${ }^{236}$ Substance abuse is correlated with having a low income, so the cost of seeing a specialist may be a significant barrier to individuals seeking treatment. ${ }^{237}$ Third, a primary care doctor is frequently the "family doctor" that the patient has been seeing for many years. ${ }^{238}$ Therefore, a primary care doctor may have a more extensive understanding of the patient's background, health history, and needs than a specialist would. Lastly, an appointment with a primary care doctor provides an extra layer of anonymity for patients suffering from drug dependence, because primary care doctors treat many different types of less stigmatized conditions. For example, seeing a psychiatrist is more stigmatized than seeing a primary care doctor. ${ }^{239}$

The reason for low DATA waiver rates among primary care doctors is not fully understood, but published studies point to a few possible explanations based on surveys and interviews with primary care doctors. ${ }^{240}$ First, many primary care doctors feel that they know too little about drug dependence to provide adequate treatment or believe that they are underqualified. ${ }^{241}$ However, DATA waiver requirements include an eight hour training course, which should somewhat ameliorate this concern. ${ }^{242}$ Furthermore, primary care provision of buprenorphine treatment is just as effective as buprenorphine treatment in more specialized settings. ${ }^{243}$ According to an article published in the Annals of Family Medicine, 54\% of patients were sober at six months of buprenorphine treatment from a primary care doctor. ${ }^{244}$ Second, some doctors fear stigma within the

236. See Shi, supra note 234 , at 10-11.

237. See Chaloupka et al., supra note 120 , at 3.

238. See Shi, supra note 235 , at 2 (stating that primary care "refers to family medicine services... and is person-oriented, longitudinal care").

239. See generally Reuven Bar-Leyav, The Stigma of Seeing a Psychiatrist, 30 AM. J. PSychotherAPy 473, 473-74 (1976).

240. See Eliza Hutchinson et al., Barriers to Primary Care Doctors Prescribing Buprenorphine, 12 AnNALS OF FAM. MED. 128 (2014).

241. Id. at 131; Saxon \& McCarty, supra note 16, at 123; Norman S. Miller et al., Why physicians are unprepared to treat patients who have alcohol- and drug-related Disorders, 76 ACAD. MED. 410, 410 (2001).

242. See U.S. Dep't of Health \& Human Servs., Buprenorphine Training FOR PHYSICIANS, http://www.samhsa.gov/medication-assistedtreatment/training-resources/buprenorphine-physician-training (2016).

243. See Ira Mintzer et al., Treating Opioid Addiction with BuprenorphineNalexone in Community-Based Primary Care Settings, 5 Annals of FAMILY MED. 146, 149 (2007).

244. See id. 
medical community for treating opioid dependent individuals, including disapproval from staff, medical partners, or institutional administration. ${ }^{245}$ Such stigma is an extension of the larger cultural phenomenon of labeling drug-dependent individuals as immoral persons rather than ill individuals. Third, some primary care doctors simply believe that they have very few patients suffering from drug dependence. ${ }^{246}$ However, this belief is probably naïve given the rising trend of opioid dependence and opioid overdoses. ${ }^{247}$ Patients with substance abuse problems may feel uncomfortable discussing their problem with their doctor, especially if they have not received any signal from the doctor suggesting that treatment is available or that such a conversation would be confidential. Fourth, doctors have described the DATA waiver process as being too time-consuming or bureaucratic. $^{248}$ However, other than an eight hour training course, there are few ongoing, time-consuming requirements for a doctor to comply with DATA after obtaining a DATA waiver. Finally, some surveyed primary care doctors have expressed apathy towards treating drug dependence. ${ }^{249}$ This attitude is probably a cover for personal bias or other reasons that that the doctor would rather not express. After all, it is difficult to imagine a physician being genuinely disinterested in treating diabetes, asthma, or another serious chronic condition for which effective medication is available.

\section{Patient Limits under DATA}

The American Medical Association and the American Society for Addiction Medicine have repeatedly criticized the patient limits in DATA $^{250}$ as being arbitrary and causing unnecessary waitlists for patients. ${ }^{251}$ Such patient limits do not exist for other Schedule III narcotics. ${ }^{252}$ They do not even exist for oxycodone, a Schedule II

245. See generally Hutchinson, supra note 240.

246. See Barry et al., supra note 84, at 222.

247. See Chen et al., supra note 1 , at 2 .

248. Hutchinson, supra note 240, at 131.

249. See Barry et al., supra note 84 , at 221.

250. See 21 U.S.C..§ 823(g).

251. See, e.g., ASAM Letter, supra note 43 ("We have at our disposal highly effective, FDA-approved pharmacotherapies to treat opioid addiction. Unfortunately, they all come with arbitrary treatment limits that have resoundingly negative effects on treatment access and outcomes."). See 151 ConG. REC. H6679-H6681 (daily ed. July 27, 2005) (Statements of Reps. Deal and Souder).

252. See Melissa Ferrara, Comment: The Disparate Treatment of AddictionAssistance Medications and Opiate Pain Medications Under the Law: Permitting the Proliferation of Opiates and Limiting Access to 
narcotic and the substance to which many opioid dependent individuals are addicted. ${ }^{253}$ In cities with buprenorphine-prescribing physicians, patient limits may cause long waitlists, sometimes with hundreds of patients. ${ }^{254}$ Buprenorphine is an effective maintenance treatment that can be used indefinitely, so once patients begin buprenorphine treatment, they are likely to have regularly scheduled appointments for a long time. As a result, persons on waitlists may need to wait many months until someone else stops treatment. ${ }^{255}$

\section{E. Bias from Mental Health Therapists}

The field of drug dependence treatment is deeply divided between individuals who support the use of MAT and individuals who oppose its use, especially within the field of counseling. ${ }^{256}$ A large minority of mental health therapists have either never heard of buprenorphine or oppose the use of buprenorphine. ${ }^{257}$

Therapists who oppose the use of buprenorphine are unlikely to educate patients about buprenorphine's availability and benefits. ${ }^{258} \mathrm{~A}$ therapist is most likely to oppose the use of buprenorphine if the therapist is philosophically aligned with abstinence-only, twelve-step groups, such as NA.259 A therapist is more likely to accept the use of buprenorphine if the therapist works in an institution that already prescribes buprenorphine. ${ }^{260}$

Mental health therapists have an important role to play in educating patients about effective drug dependence treatment. Even though mental health therapists cannot prescribe buprenorphine, they can refer patients to psychiatrists or other doctors for the medication. Counselors are already comfortable with referring patients for other medication, such as anti-depressants. For example, a survey by the American Psychological Association found that 98\% of psychologists

Treatment, 42 Seton Hall L. Rev. 741 (2012); Saxon \& McCarty, supra note 16, at 124 ("There are few, if any, other approved medications that can be prescribed only by physicians who meet certain standards.").

253. See id. at 750-52.

254. See Cherkis, supra note 16.

255. See $i d$.

256. See Knudsen et al., supra note 185.

257. See id.

258. See id.

259. See id. at 103 .

260. See id. 
have referred patients to physicians for some kind of mental health medication. ${ }^{261}$

Some mental health counselors may assume that buprenorphine and counseling are diametrically opposed. However, the most effective form of treatment for drug dependence is medication combined with mental health therapy, especially cognitive behavioral therapy. ${ }^{262}$ Furthermore, DATA recognizes the concurrent roles of medication and counseling in dependence treatment, because DATA requires a buprenorphine-prescribing physician to be able to refer a patient to ancillary mental health services. ${ }^{263}$ Likewise, methadone clinics are required to provide counseling and rehabilitative services. ${ }^{264}$

\section{F. $\quad$ Cost and Medicaid Limits}

The cost of buprenorphine treatment may serve as a disincentive for some individuals. Buprenorphine treatment has two cost components: physician visits and the prescription itself. Major commercial health insurance covers both treatment components. ${ }^{265}$ However, many patients suffering from opioid dependence are lowincome individuals, ${ }^{266}$ and, therefore, are less likely to have commercial health insurance than higher-income individuals. Also, many dependent individuals are unemployed, because a circular, causal relationship exists between unemployment and drug dependence. ${ }^{267}$ Unemployed individuals are unlikely to have commercial health insurance, because such insurance is usually obtained through one's employer. However, the ACA may make commercial insurance more accessible.

261. See Laurie Meyers, American Psychological Association, Psychologists and Psychotropic Medication, 37 MONITOR 46, 46 (2006), http://www.apa.org/monitor/jun06/psychotropic.aspx.

262. See BAXter \& Stevens, supra note 20, at 2; Vt. Agency of Human Services, supra note 20, at 2, http://www.healthvermont.gov/ adap/documents/HUBSPOKEBriefingDocV122112.pdf ("Medication assisted therapy (MAT), such as methadone and buprenorphine in combination with counseling, has long been recognized as the most effective treatment for opiate addiction."). See also What are the treatments for heroin addiction?, supra note 20.

263. See Children's Health ACt of 2000, Pub. L. No. 106-310, $\S 3502$ (codified at 21 U.S.C. $\S 823(\mathrm{~g})$ (2006 \& West Supp. 2009)).

264. Inst. of Med., Committee on Federal Regulation of Methadone Treatment 94 (Richard A. Rettig \& Adam Yarmolinsky eds.1995).

265. See Does Insurance Cover It?, supra note 95.

266. See Chaloupka, supra note 120 , at 10.

267. See Dieter Henkel, Unemployment and Substance Use: A Review of the Literature (1990-2010), 4 CurR. Drug Abuse Rev. 4, 5 (2011). 
Low-income or unemployed individuals may or may not be eligible for Medicaid, depending on the income threshold in their state for Medicaid eligibility and other state-based eligibility characteristics. States that did not choose to expand Medicaid under the ACA may bar young, single males from obtaining Medicaid coverage. Even if the patient is covered by Medicaid, some states' Medicaid programs have limits on the length of time the patient can remain on buprenorphine treatment. ${ }^{268}$ These "lifetime limits" may be as short as 1 year. ${ }^{269}$ Medical authorities are strongly opposed to such limits, because longterm buprenorphine treatment is more effective than short-term buprenorphine treatment. ${ }^{270}$

Buprenorphine treatment requires regular physician visits. Because buprenorphine is a Schedule III narcotic, the federal government allows automatic refills for up to 6 months or 5 refills. ${ }^{271}$ However, in practice, many physicians do not prescribe automatic refills, and instead require that the patient return for an appointment monthly. ${ }^{272}$ Specialists are more likely than primary care doctors to have a DATA waiver, so chances are that a patient undergoing buprenorphine treatment will need to regularly pay for an appointment with a specialist. ${ }^{273}$ Unfortunately, appointment costs (with or without health insurance) tend to be more expensive for specialists than for primary care doctors. ${ }^{274}$ This cost could act as a disincentive to begin or continue buprenorphine treatment.

The cost of the medication, as discussed in Part II, varies widely. The monthly cost depends on whether or not the patient has health

268. Robin E. Clark et al., supra note 96, at 1425-26.

269. See Substance Abuse \& Mental Health Servs. Admin., Coverage and Financing of Medications to Treat Alcohol and Opioid Use DisORDERS 19 (2014), http://store.samhsa.gov/shin/content//SMA144854/SMA14-4854.pdf.

270. See id.

271. See 21 C.F.R. $\S 1306.22$.

272. See 15 Ways to Save Money on Buprenorphine Treatment, supra note 83 ("As the patient stabilizes, s/he can request to have less frequent office visits. Although physicians commonly require patients to come in for appointments every month to monitor the patient's progress, schedule III medications can be refilled up to 5 times in a 6 month period. Visit frequency is ultimately determined by the physician, but it doesn't hurt to ask, particularly for those stable in long-term addiction remission and those who get therapy or counseling from other sources. Some states however, overrule the physician's judgment and have set minimum periods between office visits.").

273. See Rosenblatt et al., supra note 232, at 24 .

274. See generally Shi, supra note 234 , at 10-12. 
insurance coverage or Medicaid, purchases generic Suboxone, or pays with a discount card from a pharmaceutical company. ${ }^{275}$

\section{G. Concerns of Diversion}

Some major newspapers have published articles regarding diversion and abuse of buprenorphine, possibly discouraging some physicians from prescribing it. ${ }^{276}$ Buprenorphine can be overdosed or abused. However, buprenorphine overdoses are rare relative to heroin, oxycodone, or methadone overdoses. ${ }^{277}$ There are two reasons for this. First, the partial mu-antagonist nature of buprenorphine prevents the patient from experiencing euphoria from taking any additional opioid (including extra buprenorphine). ${ }^{278}$ Second, buprenorphine is far less potent than heroin, oxycodone, methadone, and other common opioids. ${ }^{279}$

Buprenorphine is sometimes diverted to the black market (sold on the street). However, some recent studies have found that individuals who purchase buprenorphine on the black market are more likely to do so in order to help themselves become sober (i.e. as treatment) rather than to get "high." 280 These individuals may find it easier to purchase buprenorphine illicitly than to obtain an appointment with a buprenorphine-prescribing doctor. ${ }^{281}$ The bizarre fact that a black market has developed for treatment medication points to the high demand for treatment relative to the supply of providers. ${ }^{282}$

\section{The TrEAT ACT}

In 2013, Senator Markey introduced The Recovery Enhancement for Addiction Treatment Act (TREAT Act), Bill S. 2645 (2013), which has the potential to significantly expand access to

275. See infra Part II.C.

276. See, e.g., Deborah Sontag, Addiction Treatment with a Dark Side, N.Y. Times (Nov. 16, 2013), http://www.nytimes.com/2013/11/17/health/indemand-in-clinics-and-on-the-street-bupe-can-be-savior-ormenace.html?pagewanted $=$ all \&_ $\mathrm{r}=0$.

277. See generally About Buprenorphine Treatment, supra note 75.

278. See $i d$.

279. See id.

280. Zev Schuman-Olivier et al., Self-Treatment: Illicit Buprenorphine Use by Opioid-Dependent Treatment Seekers, 39 J. Substance Abuse 41, 43 (2010).

281. See id.

282. See id. 
buprenorphine treatment. ${ }^{283}$ Bill S. 2645 (2013) version never made it past committee. However, the TREAT Act has been reintroduced in the Senate in 2015 as Bill S. 1455 (2015), with a corresponding version introduced in the House of Representatives, Bill H.R. 2536 (2015). ${ }^{284}$ Part A of this section outlines the contours and objectives of the proposed TREAT Act. Part B discusses the benefits of the proposed Act. Part $\mathrm{C}$ offers some suggestions for strengthening the TREAT Act, so that it can better address reasons for buprenorphine's underuse.

\section{A. Proposed Provisions of the TREAT Act:}

The purpose of the TREAT Act is to increase access to buprenorphine treatment for individuals dependent on opioids. ${ }^{285}$ Consequentially, the TREAT Act is intended to reduce deaths from opioid overdose, criminal activity, and HIV-transmission associated with opioid injections. ${ }^{286}$ If passed, the TREAT Act would substantively amend the CSA in two ways. First, it would allow qualified nurse practitioners and physician assistants to provide buprenorphine treatment. ${ }^{287}$ Second, it would allow practitioners to treat far more patients by increasing the patient limit threshold..$^{288}$

1. Expansion of the Definition of Practitioner

The TREAT Act would allow any "qualifying practitioner" to prescribe buprenorphine. ${ }^{289}$ Under DATA, only a licensed physician may become a qualified practitioner, but the TREAT Act would allow certain licensed physician assistants and nurse practitioners to

283. See also Recovery Enhancement for Addiction Treatment Act, S.2645, 113th Congress (2014).

284. See Major

Actions-

Recovery Enhancement for Addiction Treatment Act, S.1445, CONGRESS.GOV (2015), https://www.congress.gov/bill/114th-congress/ senate-bill $/ 1455 /$ all-actions? $\mathrm{q}=\{\% 22$ search $\% 22 \% 3 \mathrm{~A}[\% 22 \mathrm{RECOVERY}+$ ENHANCEMENT+FOR+ADDICTION+TREATMENT+ACT+S2645 $\% 22]$ \} \&resultIndex $=2$ (last visited October 20, 2015) ("Read twice and referred to the Committee on Health, Education, Labor, and Pensions."); Major Actions - Recovery Enhancement for Addiction Treatment Act, H.R. 2536, Congress.gOV (2015), https://www. congress.gov/bill/114th-congress/house-bill/2536/all-Actions? $\mathrm{q}=\{\% 22 \operatorname{search} \% 22 \% 3 \mathrm{~A}[\% 22 \backslash \% 22 \mathrm{hr} 2536 \backslash \% 22 \% 22]\} \&$ resultIndex $=1$.

285. See $i d$.

286. See id.

287. See Recovery Enhancement for Addiction Treatment Act, S.1445 §3, 113th Cong. (2015).

288. See id.

289. See id. 
Health Matrix · Volume 26 Issue $1 \cdot 2016$

America Needs the TREAT Act:

Expanding Access to Effective Medication for Treating Addiction

also become qualified practitioners. ${ }^{290}$ The bill refers to them as "qualified physician assistants and nurse practitioners." 291 In order to become qualified, a physician assistant or nurse practitioner must meet all of the following criteria:

(i) be licensed under state law to prescribe Schedule III, IV, or $\mathrm{V}$ medications for pain; and

(ii) have completed at least 24 hours of training in addiction medicine (or have experience the Secretary deems to be equivalent); and

(iii) practice under a physician who both

a. holds an active waiver to prescribe buprenorphine; and

b. fulfills one of the following criteria:

i. is board certified as an addiction medicine specialist by

a medical association listed in the statute, or

ii. practices in a qualified health care setting. ${ }^{292}$

The supervising physician requirement is quite restrictive, but easy to overlook if one quickly reads the statute. ${ }^{293}$ Not every physician with a DATA waiver can supervise physician assistants or nurse practitioners. ${ }^{294}$ To become a supervising physician, the physician must be "board certified" as an addiction specialist by one of the listed medical authorities (such as the American Society of Addiction Medicine), or must practice in a qualified health setting. ${ }^{295}$ There is a list of qualified practice settings in Section 4(2) of the Act, including the following settings: an Accountable Care Organization, a Department of Veterans Affairs clinic, and prison clinics. ${ }^{296}$

In other words, a physician who merely completed the eight hour certification course may himself or herself prescribe buprenorphine, but he or she may not act as "supervisor" for a nurse practitioner or physician assistant for purposes their qualification under the Act. ${ }^{297}$

290. See id.

291. See id.

292. See id.

293. See id.

294. See id. at 4(1).

295. See id.

296. See id. at $\S 4(2)$.

297. See id. 
Presumably, the sponsors of the TREAT Act are concerned with the quality of supervision that a physician who only took a brief addiction treatment certification course could provide to nurse practitioners or physician assistants. ${ }^{298}$

\section{New Patient Limits}

Under DATA, a physician may treat up to 30 patients during her first year of having a DATA waiver, and 100 patients thereafter. ${ }^{299}$ The TREAT Act, on the other hand, would allow a qualifying practitioner (whether a physician, nurse practitioner, or physician assistant) to treat up to one hundred patients during the first year. ${ }^{300}$

After the first year, the TREAT Act would allow the qualifying practitioner to submit a notification to the Secretary of Health signifying the need and intent to treat an unlimited number of patients. ${ }^{301}$ The Secretary would then permit the qualifying practitioner to treat an unlimited number of patients, so long as the practitioner meets all of the criteria of one of the following paths. ${ }^{302}$

\section{a. Path 1: Practitioners Qualifying via Board Certification}

The first path only applies to practitioners who became qualified to treat 100 patients by virtue of having a Board Certification as an addiction medicine specialist from a medical authority listed in the statute (such as the American Society for Addiction Medicine). ${ }^{303}$ The practitioner only needs to participate in the Prescription Drug Monitoring Program of the State in which the practitioner is licensed. ${ }^{304}$

\section{b. Path 2: Practitioners Qualifying via Training Course, Investigating} a Clinical Trial, or Other Methods

An alternate path is for practitioners who are already qualified to treat 100 patients by virtue of having either taken an eight hour training course, acted as an investigator in a clinical trial of buprenorphine (or similar medication), or otherwise convinced the U.S. Secretary of Health and Human Services or state medical board of their ability to treat opioid-addicted patients. ${ }^{305}$

298. See $i d$.

299. See id., at $\S 3$.

300. See id., at $\S 3-4$.

301. See id., at $\S 3$.

302. See id.

303. See id.

304. See id.

305. See id. 
Health Matrix · Volume 26 Issue $1 \cdot 2016$

America Needs the TREAT Act:

Expanding Access to Effective Medication for Treating Addiction

In order to satisfy this path, the practitioner must meet all of the following criteria:

(a) Participate in the Prescription Drug Monitoring Program of the State in which the practitioner is licensed; and

(b) Practice in a qualified setting (defined in 4 (II)(cc)(BB)); and

(c) Complete at least 24 hours of addiction medicine training (including the 8 hours already taken). ${ }^{306}$

\section{B. Discussion of the TREAT Act}

\section{Why it's Good}

The TREAT Act is supported by a long list of American medical authorities, including the following: the American Medical Association, the American Society of Addiction Medicine, the American Association of Nurse Practitioners, the Association of American Medical Colleges, Trust for America's Health, the National Association of State Alcohol and Drug Abuse Directors, and the National Association of County and City Health Officials. ${ }^{307}$ However, the general public and popular media hardly seem to have noticed the proposed bill. ${ }^{308}$

The TREAT Act is good for physicians, because it would allow them to treat more patients with buprenorphine, thus effectively increasing the benefits of obtaining a DATA waiver relative to the costs of obtaining a waiver. The TREAT Act is also good for opioid dependent individuals who are seeking treatment, because they will have an easier time obtaining an appointment for buprenorphine treatment if more practitioners are available (in the form of nurse practitioners and physician assistants) and if patient limits are loosened.

In July of 2014, the president of the American Society of Addiction Medicine, Stuart Gitlow, sent a letter to Senator Markey commending the proposed TREAT Act for its potential to improve access to treatment by increasing the number of buprenorphinetreatment practitioners. ${ }^{309}$ The letter states that approximately 5000

306. See id.

307. See Senator Edward Markey, The Recovery Enhancement for Addiction Treatment Act (TREAT Act) (2015), http://www.markey.senate.gov/ imo/media/doc/2015-05-27-OnePager-TREAT-Act-.pdf.

308. A Google search by the author on February 9, 2015, did not result in any mainstream newspaper headlines regarding the TREAT Act.

309. See, e.g., ASAM Letter, supra note 43. 
board certified addiction physicians are currently trained to treat opioid dependence, but,

There are tens of thousands more primary care physicians and advanced practice clinicians like nurse practitioners and physician assistants who, with significant specialized training and access to the aforementioned specialists, can also advance the use of buprenorphine and thereby help fill the treatment gap. ${ }^{310}$

The letter also commends the TREAT Act for decreasing patient limits and eliminating them altogether for certain qualified practitioners. ${ }^{311}$ According to Gitlow's letter, the current restrictions on this "life-saving medication" are "arbitrary." 312

The expansion of the definition of "qualified practitioners" to include nurse practitioners and physician assistants is a critical step in increasing access to buprenorphine. Today many cities do not have a single physician with a DATA waiver, ${ }^{313}$ and many physicians with DATA waivers have very long waitlists. The Huffington Post recently stated that one Ohio county clinic has a waitlist of over 500 patients. $^{314}$

Likewise, the change in patient limits from 30 to 100 in the first year and from 100 to an unlimited number in the second year has the potential to dramatically shorten waitlists for patients. ${ }^{315}$ In theory, Americans should be deeply concerned about the waitlists that many opioid-dependent individuals must face when seeking treatment. After all, the popular media criticizes waitlists in other countries, even when those waitlists are for elective procedures. ${ }^{316}$ Buprenorphine, on the other hand, is life-saving, essential medicine. ${ }^{317}$ Furthermore, buprenorphine treatment has been found to reduce

310. $I d$.

311. See id.

312. Id.

313. See Rosenblatt, supra note 233, at 25.

314. See Cherkis, supra note 16.

315. See Recovery Enhancement for Addiction Treatment Act S.2645, 113th Congress (2014).

316. See, e.g., David Frum, How Long Do Canadians Wait for Healthcare?, DAILY BEAST (Jun. 20, 2012), http://www.thedailybeast.com/ articles/2012/06/20/canadian-healthcare.html. See also Queue-Jumping a Fact, Alberta Medical Inquiry Finds, CBC News (Aug. 21, 2013), http://www.cbc.ca/news/canada/calgary/queue-jumping-a-fact-albertamedical-inquiry-finds-1.1393856.

317. See, e.g., WHO Model List of Essential Medicines, supra note 40. 
drug-related crime, ${ }^{318}$ health care costs (particularly for emergency room visits), and unemployment. ${ }^{319}$

The point at which an opioid-dependent individual recognizes that he or she has a problem and seeks help is an absolutely critical window that can quickly disappear. ${ }^{320}$ It is a tragedy for a person with a debilitating addiction to recognize that he or she needs help but is unable to obtain it due to government-mandated patient limits. The cravings for opioids and the withdrawal symptoms a person experiences when they try to become sober may quickly overcome the desire to seek treatment if an appointment with a physician cannot be obtained.

The TREAT Act would not only help save the lives of addicted individuals, it would also be a tremendous relief to their families. Few circumstances are more tragic than seeing a spouse, parent, child, or sibling suffer from a deadly chronic disease, especially one that frequently leads to lack of employment and incarceration. Families too frequently bear the financial and emotional burden of having to support individuals struggling with drug dependence.

\section{How to Make the TREAT Act Great}

With some hesitation, this article's author would recommend four additions to the proposed TREAT Act. The hesitation stems from the fact that the legislative process of proposing amendments could cause the passage of the Act to become severely delayed or even completely derailed in one of many potential legislative "vetogates," ${ }^{21}$ The bill is co-sponsored by Senators Feinstein (D), Rockefeller (D), Brown (D), Hirono (D), and Durbin (D). ${ }^{322}$ Unlike the bipartisan sponsors of DATA, the co-sponsors of the TREAT Act are all

318. See Erol Digiusto et al., Effects of Pharmacotherapies for Opioid Dependence on Participants' Criminal Behavior and Expenditure on Illicit Drugs: An Australian National Evaluation (NEOPD), 39 AusTL. \& N.Z. J. CRIMinology 171, 172, 183-85 (2006).

319. See generally Amine Khemiri et al., Analysis of buprenorphine/nalexone dosing impact on treatment duration, resource use, and costs in the treatment of opioid dependent adults: a retrospective study of U.S. public and private health care claims, 126 PostgRAD. MED. J. 113 (2014).

320. See Detoxification and Substance Abuse Treatment Training Manual, Substance Abuse \& Mental Health Servs. Admin. 13 (2008), http://store.samhsa.gov/shin/content/SMA09-4331/SMA09-4331.pdf; Stöver, supra note 23 , at 45.

321. See William Eskridge, Vetogates and American Public Law, J. LAW ECON. ORG. ${ }^{*} 3$ (2012).

322. See Recovery Enhancement for Addiction Treatment Act, S.2645, 113th Congress (2014). 
Democrats. ${ }^{323}$ At the time of this article's writing, the bill is in the Senate Committee on Health, Education, Labor, and Pensions, ${ }^{324}$ which is chaired by Senator Alexander (R). The committee has a slight Republican majority (12 Republicans versus 10 Democrats), but it includes Senator Hatch (R) who proposed the original version of DATA. ${ }^{325}$ In this current era of extremely polarized politics, any amendment could derail the bill. Sometimes it is better to simply allow a "good" bill to become law than to propose changes to make it "great."

With that caveat in mind, this author would propose the following four additional provisions to the TREAT Act: a) significantly increased federal funding for grants used to educate health practitioners and the public about evidence-based addiction treatment; b) financial incentives for Medicaid to cover buprenorphine without lifetime limits; c) federal block grants to states that agree to cover the cost of the eight hour training course necessary for many health practitioners to obtain a DATA waiver; and d) federal grants for studying both the reasons for underutilization of addiction medicine and potential government policies to increase its utilization.

\section{a. Federal Funding for Educational Grants}

First, the TREAT Act should significantly increase funds in the form of grants to cities, universities, and non-profit organizations to educate citizens, physicians, nurse practitioners, physician assistants, hospitals, in-patient and out-patient rehabilitation centers, and mental health therapists about the proven benefits of evidence-based treatment for opioid-dependence, including buprenorphine. ${ }^{326}$ Many primary care doctors never seek a DATA waiver simply because they do not know about buprenorphine or feel that they lack the knowledge to provide treatment. ${ }^{327}$ This is not surprising, given that most medical students receive little education in addiction medicine. ${ }^{328}$

323. Id.

324. Major Actions: S. 2645 - 113 th Congress (2013-2014), CONGRESs.GOV, https://www.congress.gov/bill/113th-congress/senate-bill/2645/ actions?q=\%7B\%22search $\% 22 \% 3 \mathrm{~A} \% 5 \mathrm{~B} \% 22 \mathrm{RECOVERY+ENHANCEM}$ $\mathrm{ENT}+\mathrm{FOR}+\mathrm{ADDICTION}+\mathrm{TREATMENT}+\mathrm{ACT} \% 22 \% 5 \mathrm{D} \% 7 \mathrm{D}$ (last visited Feb. 10, 2015).

325. U.S. Senate Committee on Health, Education, Labor, AND Pensions, http://www.help.senate.gov/ (last visited Feb. 10, 2015).

326. See, e.g., Matusow, supra note 12, at 479 (arguing that there is a "critical need for a strong educational initiative to disseminate evidence about MAT efficacy in treating opioid dependence.").

327. See Barry, supra note 84.

328. See Cherkis, supra note 16. See also Ellen Weber, Symposium: Failure Of Physicians To Prescribe Pharmacotherapies for Addiction: 
However, studies show that buprenorphine works well for opioiddependent individuals who see primary care physicians ${ }^{329}$ (most of whom only take the 8 hour course required by DATA)..$^{330}$ Therefore, many primary care doctors' fear of being underqualified is largely unfounded. ${ }^{331}$

Additionally, a large minority of mental health counselors do not know about buprenorphine or oppose the use of buprenorphine treatment. $^{332}$ According to one survey, $41 \%$ of mental health counselors do not consider buprenorphine to be an acceptable treatment, and $54 \%$ do not consider buprenorphine to be an effective treatment. ${ }^{333}$ An educational initiative with accurate medical data about evidence-based treatment may help many of these counselors refer their patients to a physician for buprenorphine treatment. Finally, Americans in general should be educated about treatment options rather than only being warned about the dangers of drugs. The U.S. government has previously created mass media campaigns to inform the public of the dangers of smoking and drugs. ${ }^{334}$ These same types of campaigns could incorporate information about effective treatment for drug dependence, including buprenorphine. Furthermore, by openly talking about medications like buprenorphine, a mass educational campaign could help eliminate some of the stigma of MAT.

This suggested amendment to the TREAT Act might not be cost neutral. The Congressional Budget Office will probably find it difficult to quantify the benefits of educational grants relative to their cost, especially because information diffusion takes time. However, increased public knowledge about buprenorphine will almost certainly lead to increased use of buprenorphine. Increased use of buprenorphine will lead to fewer medical, law enforcement, and unemployment expenditures by federal and state governments, ${ }^{335}$ potentially offsetting costs of increasing educational grants.

Regulatory Restrictions and Physician Resistance, 13 J. Health Care L. \& Pol'y 49, 69 (2010).

329. See Mintzer et al., supra note 240, at 150.

330. Primary care doctors are unlikely to be Board Certified as Addiction Specialists, so most primary care physicians with a DATA waiver probably took a certification course, as permitted under DATA.

331. See Mintzer et al., supra note 243.

332. See Knudsen et al., supra note 185, at 98.

333. See Rieckmann et al., supra 185 at 377.

334. See, e.g., National Youth Anti-Drug Media Campaign, THE WhITE House, http://www.whitehouse.gov/ondcp/anti-drug-media-campaign (last visited Feb. 9, 2015).

335. See infra Part II.C. 


\section{b. Financial Incentives for Medicaid Coverage of Addiction Medicine}

Second, the TREAT Act should encourage Medicaid programs to cover buprenorphine indefinitely for Medicaid eligible individuals who have a formal medical diagnosis of opioid dependence. For example, the federal government could agree to bear part of the cost of Medicaid beneficiaries' generic buprenorphine prescriptions, while prohibiting the state from placing lifetime limits on buprenorphine maintenance treatment.

According to the National Institute on Drug Abuse (NIDA), approximately $12 \%$ of Medicaid beneficiaries over the age of eighteen have a substance use disorder. ${ }^{336}$ When Medicaid beneficiaries with substance use problems receive MAT, including buprenorphine, Medicaid spends 33\% less on their health care costs over the first three years, and costs continue to decline thereafter. ${ }^{337}$ Medicaid is a block-grant program between the federal government and state governments, so costs savings would be shared between the federal government and state governments. Medicaid accounts for the single largest expenditure of states' revenues, so increasing access to MAT could significantly decrease total state Medicaid costs, pleasing both cultural liberals and fiscal conservatives.

According to SAMHSA, eleven states' Medicaid programs set lifetime limits on buprenorphine treatment. ${ }^{338}$ Medicaid programs rarely set lifetime limits on medications for other chronic diseases, suggesting institutional bias against drug-dependent individuals. ${ }^{339}$ In the case of buprenorphine, lifetime limits negatively affect patient safety. ${ }^{340}$ According to a study published in Health Affairs, "mortality rates were... more than twice as high among those receiving no treatment, compared to those receiving buprenorphine [through Medicaid]." ${ }^{341}$ Medical studies show that drug abuse relapse is most

336. See Informational Bulletin, supra note 39, at, 1 .

337. See id.

338. Substance Abuse \& Mental Health Servs. Admin., Medicaid Coverage and Financing of Medications to Treat Alcohol and OPIOID USE DISORDERS 2 (2014), http://store.samhsa.gov/shin/ content//SMA14-4854/SMA14-4854.pdf.

339. See id.

340. See Clark et al., supra note 80, at 1431 ("Although further studies measuring the impact of policies that restrict access to buprenorphine are needed, this analysis suggests that significant reductions in its use could have the unintended effect of increasing costs. Also, if it reduces overall use of opioid substitution therapy, a policy restricting buprenorphine use might also contribute to higher mortality among Medicaid beneficiaries with opioid addiction.").

341. Id. at 1425 . 
effectively prevented by long-term buprenorphine maintenance treatment, not short-term treatment. ${ }^{342}$ For example, a randomized study found that $90 \%$ of patients relapse if buprenorphine treatment stops after 12 weeks. ${ }^{343}$ Therefore, individuals who lose Medicaid coverage for buprenorphine treatment have a high risk of relapse. ${ }^{344}$

Not only is relapse harmful to the individual, it is bad for the state budget. When individuals relapse, they are more likely to need expensive emergency room treatment, in-patient rehabilitation, and/or hospital treatment due to opioid overdose. ${ }^{345}$ According to the CDC, every day approximately 7,000 individuals seek emergency room treatment for substance abuse-related medical emergencies. ${ }^{346}$ Additionally, individuals who relapse are more likely to become unemployed than those who do not relapse, ${ }^{347}$ causing a loss in economic productivity. Finally, individuals who relapse are more likely to commit drug-related crimes ${ }^{348}$ draining state law enforcement resources.

\section{c. Grants for Physician Certification Courses}

Third, the TREAT Act should authorize the federal government to provide block grants to states that agree to at least partially cover the cost of the eight-hour certification course necessary for most health practitioners to obtain a DATA waiver. $^{349}$ The federal government would bear the remaining cost. As a result, more

342. See Roger D. Weiss et al., Adjunctive counseling during brief and extended buprenorphine-naloxone treatment for prescription opioid dependence: A 2-phase randomized controlled trial, 68 ARCH. GEN. PSYCHIATRY 1238, 1238 (2011) (explaining that relapse is prevented while patients are on buprenorphine, but significantly increases if patients taper off buprenorphine).

343. See id at 1244 .

344. See id. at 1238 .

345. See CDC, Prescription Drug Overdose in the United States: Fact SHEET, http://www.mayorsinnovation.org/images/uploads/pdf/1__Prescription_Drug_Overdose_in_the_United_States.pdf (last visited Feb. 9, 2015) ("Every day in the United States, 114 people die as a result of drug overdose, and another 6,748 are treated in emergency departments (ED) for the misuse or abuse of drugs.").

346. See id.

347. Regarding the relationship between addiction and unemployment, see generally Henkel, supra note 267.

348. Cf. Redonna Chandler et al., Treating Drug Abuse and Addiction in the Criminal Justice System: Improving Public Health and Safety, 301 JAMA 183 (2009).

349. See Recovery Enhancement for Addiction Treatment Act, S.2645, 113th Congress (2014). 
physicians, nurse practitioners, and physician assistants would be more likely to seek a DATA waiver. A primary care doctor would need to take such a course in order to obtain a DATA waiver, as he or she is unlikely to already be board certified as an addiction specialist. ${ }^{350}$ As discussed in Part IV, infra, primary care doctors are an ideal gateway to addiction treatment, because they have lower fees than specialists and are typically the sole physicians in rural areas.

The block grants could be authorized as a pilot program requiring review after one year. That way, the federal and state governments could assess how effective such a program was at inducing primary care physicians to obtain a DATA waiver. Funding of one physician's certification course would allow that physician to treat 100 patients in the first year under the TREAT Act. ${ }^{351}$ Many of the patients are likely to be Medicaid beneficiaries. ${ }^{352}$ As discussed previously, Medicaid costs decline for beneficiaries with substance abuse problems once these beneficiaries receive MAT. ${ }^{353}$ Because Medicaid is a block grant program between the federal government and state governments, both would benefit from savings in Medicaid costs.

d. Grants to Study Addiction Medicine Underuse

Finally, the TREAT Act should increase federal funding for grants to research reasons for the underutilization of MAT and methods to incentivize its use. Existing but insufficient funding is available through the National Institute of Drug Abuse. Scholars should examine the practices, attitudes, norms, and beliefs of decisionmakers in the criminal justice system, health practitioners, and the general public. Most importantly, more legal, criminal justice, and health policy researchers should analyze potential government policies for expanding the use of MAT.

This amendment to the TREAT Act would not be cost neutral. It will be difficult for the Congressional Budget Office to quantify and predict the benefits of grants to study underuse of MAT. However, the information gathered would allow policy makers to tailor treatment incentives to targeted populations. For example, currently few state prisons and only half of drug courts offer buprenorphine treatment, largely due to stigma against MAT. ${ }^{354}$ Federal policy makers should learn the reasons for abstinence-only treatment preferences within states' criminal justice systems. Then, they could

350. See id.

351. See id., at §3-4.

352. See Informational Bulletin, supra note 39.

353. See $i d$.

354. See Nunn, supra note 31 , at 85-86. 
specifically address those concerns when creating federal incentives to expand MAT. In the long-run, increased use of MAT in the criminal justice system, whether state or federal, will lead to lower recidivism, incarceration rates, and costs. ${ }^{355}$

\section{Conclusion}

Medication combined with mental health counseling has been considered the standard of care for treating opioid dependence for decades. ${ }^{356}$ Unfortunately, the public, many doctors, and a large minority of mental health therapists do not seem to have noticed. There are three FDA-approved medications for treating opioid dependence: methadone, buprenorphine, and extended release naltrexone..$^{357}$ This article focuses on buprenorphine, because it is the most cost-effective and widely used medication assisted treatment. ${ }^{358}$ Buprenorphine is a life-saving medication that has been proven to decrease relapse, criminal activity, unemployment, and mortality. ${ }^{359}$ It is considered an essential medicine by the World Health Organization. ${ }^{360}$

Buprenorphine treats opioid dependence by partially activating and partially blocking the opioid receptor in the brain, thus reducing cravings, preventing withdrawals, and preventing euphoria from opioids. ${ }^{361}$ Even though reports of diversion and abuse of buprenorphine exist, studies have found that when buprenorphine is purchased on the street, it is usually used to get sober, not to get "high." "362

355. See id. at 87.

356. See generally Medication-Assisted Treatment For Opioid ADDICTION, supra note 27, at 5 .

357. See id., at 26.

358. For a comparison of cost-effectiveness of buprenorphine, Vivitrol, and methadone, see Kaskutas, supra note 17.

359. See Nicholas Zaller et al., Initiation of Buprenorphine during Incarceration and Retention in Treatment Upon Release, $45 \mathrm{~J}$. Substance Abuse Treatment 222, 222 (2013).

360. See WHO Model List of Essential Medicines, supra note 40.

361. See The Facts about Buprenorphine for Treatment of Opioid Addiction, supra note 78 , at 3 .

362. See Z. Schuman-Olivier et al., Self-Treatment: Illicit Buprenorphine Use by Opioid-Dependent Treatment Seekers, 39 J. SubSTAnCE Abuse 41, 46 (2010). 
Buprenorphine was approved by the FDA in $2002 .{ }^{363}$ Shortly before its approval, the DEA rescheduled it from schedule $\mathrm{V}$ to Schedule III. In 2000, Congress passed the Drug Addiction and Treatment (DATA). ${ }^{364}$ DATA permitted physicians to prescribe buprenorphine for opioid dependence treatment, but it also placed strict limits on buprenorphine treatment. ${ }^{365}$ After two amendments, DATA currently allows physicians with a DATA waiver to treat up to 30 patients during their first waiver year, and up to 100 patients thereafter. ${ }^{366}$ Unfortunately, very few physicians actually have a DATA waiver, and the waiting lines for these physicians can be very long. ${ }^{367}$ Even though any licensed physician who obtains a DATA waiver can prescribe buprenorphine, most physicians with DATA waivers are specialists, not primary care doctors. ${ }^{368}$ This is unfortunate, as patients tend to have better access to primary care doctors than to specialists, due to financial and geographic barriers. ${ }^{369}$

Buprenorphine is underutilized in the U.S. Reasons include the following: cultural stigma against MAT; bias from Narcotics Anonymous (NA) and many mental health counselors against MAT; the dominant cultural paradigm of "abstinence-only" treatment; cost; Medicaid limits; patient limits and other restrictions in DATA; and concerns about diversion. ${ }^{370}$

The TREAT Act was first introduced in the Senate in 2013 by Senator Markey (D). ${ }^{371}$ It was reintroduced in both the Senate and the House of Representatives in 2015. The TREAT Act would amend current law in two fundamental ways. First, it would allow nurse practitioners and physician assistants who meet statutory

363. See Subutex and Suboxone Approved to Treat Opiate Dependence, FooD \& Drug Admin. (Oct. 8, 2012), http://www.fda.gov/Drugs/ DrugSafety/PostmarketDrugSafetyInformationforPatientsandProviders/ ucm191521.htm.

364. 21 U.S.C. $\S 823(\mathrm{~g})$.

365. See $i d$.

366. See $i d$. DATA was first amended by the Drug Addiction Treatment Expansion Act, 151 Cong Rec D 877, 151 Cong Rec D 877 (2005). It was then amended by The Office of National Drug Control Policy Reauthorization Act of 2006, Public L. 109-469 (2006).

367. See Cherkis, supra note 16. See also Saxon \& McCarty, supra note 16, at 122 .

368. See Rosenblatt, supra note 232, at 25.

369. See id.

370. See infra Part V.

371. See Recovery Enhancement for Addiction Treatment Act, S.2645, 113th Congress (2014). 
Health Matrix · Volume 26 Issue $1 \cdot 2016$

America Needs the TREAT Act:

Expanding Access to Effective Medication for Treating Addiction

requirements to prescribe buprenorphine. ${ }^{372}$ Second, it would allow qualified practitioners to treat up to 100 patients at any time during the first waiver year and to treat an unlimited number of patients thereafter. ${ }^{373}$ By allowing more health practitioners to prescribe buprenorphine and by loosening patient limits, the TREAT Act has the potential to increase public access to buprenorphine. For these reasons, the TREAT Act has had strong support from physician associations. ${ }^{374}$

Even with its many benefits, the TREAT Act is still only a step in the right direction. As this article suggests, the Act would benefit from the several key additions. First, there must be increased federal funding for educational grants. Second, there must be federal financial incentives for states to remove Medicaid lifetime-limits on buprenorphine treatment Next, the Act should provide for federal block grants to partially cover the costs of the certification course required for some health practitioners Finally, the TREAT Act should increase federal funding for grants to study underuse of MAT and methods to expand its use. With these modifications, the TREAT Act would be a stronger response to the opioid crisis facing America.

372. See id.

373. See id.

374. See, e.g., ASAM Letter, supra note 43. 